\title{
Integrated 3D geophysical and geological modelling of the Kautokeino Greenstone Belt in Finnmark, northern Norway
}

Aziz Nasuti ${ }^{1}$, Odleiv Olesen ${ }^{1}$, Yuriy Maystrenko ${ }^{1}$, Alexandros Stampolidis ${ }^{2}$, Vikas C. Baranwal ${ }^{1}$

${ }^{1}$ Geological Survey of Norway, P.O.Box 6315 Torgarden, 7491 Trondheim, Norway

${ }^{2}$ Geophysical Laboratory, Aristotle University of Thessaloniki, GR 540 06, Thessaloniki, Greece.

E-mail corresponding author (Aziz Nasuti): aziz.nasuti@ngu.no

Keywords:

- Kautokeino Greenstone Belt

- Finnmark

- 3D geophysical modelling

- Gravity and magnetic data

- Northern Norway

Received:

23. April 2021

Accepted:

5. October 2021

Published online:

12. January 2022
A new 3D crustal-scale model has been created for the Kautokeino Greenstone Belt (KKGB) in northern Norway based on 3D density modelling and aeromagnetic data, integrated with qualitative interpretation of geophysical and geological data. Detailed geophysical analyses and their integration with an existing petrophysical database allowed us to identify and interconnect shallow and deeper structures throughout the study area. To have better control on the regional tectonic setting of the KKGB, the model area has been extended to include the northern part of Finland and Sweden. The new 3D density model reveals that the KKGB is broader than supposed previously. The 3D analysis indicates that the belt reaches depths of approximately 5-6 km and is emplaced as a highly deformed structure between the Archaean Jergul Gneiss Complex (JGC) to the east and the Rommaeno Gneiss Complex (RoGC) in Finland to the west. The Ráiseatnu Gneiss Complex (RaGC) in the western part of the KKGB is characterised by a dominant NNW-SSE magnetic trend that is sub-parallel to the main trend of the KKGB. Moreover, the RaGC is similar to the KKGB in terms of the presence of a large number of sub-parallel magnetic anomalies. This gneiss complex shows mostly short-wavelength anomalies and some circular anomalies that differ from the more subdued and irregular anomaly pattern of the JGC and RoGC. In the new 3D model, the RaGC is assumed to constitute a migmatised part of the Kautokeino Greenstone Belt. At a large scale, this Proterozoic greenstone belt has some similarities to Archaean counterparts, where most of the deformation is caused by gravitational tectonics. This study shows that careful integration of geological and geophysical data can strongly improve the 3D understanding of the complex, poorly exposed, Precambrian terranes of the Finnmarksvidda region in Norway.
Nasuti, A., Olesen, O., Maystrenko, Y., Stampolidis, A. \& Baranwal, V. C. 2021: Integrated 3D geophysical and geological modelling of the Kautokeino Greenstone Belt in Finnmark, northern Norway. Norwegian Journal of Geology 101, 202114. https://dx.doi.org/10.17850/njg101-3-4. 


\section{Introduction}

The Palaeoproterozoic Kautokeino Greenstone Belt (KKGB) in Finnmark (northern Norway) is a NNW-SSE-trending belt composed mostly of mafic metavolcanic sequences and associated supracrustal rocks (Holmsen et al., 1957; Solli, 1983; Olesen \& Solli, 1985; Olsen \& Nilsen, 1985; Siedlecka et al., 1985; Sandstad, 1992; Olesen \& Sandstad, 1993; Torske \& Bergh, 2004). Despite the long study of the KKGB, there is still a limited understanding of both deep and partially surface structures. The problem is that the Finnmarksvidda area is heavily covered with glacial drift. In this case, regional geophysical data are a prerequisite to structural analysis and geological interpretation. Olesen \& Solli (1985) and Olesen \& Sandstad (1993) combined geophysical and geological data to reconstruct a tectonic history of the area. They created five 2D gravity models of the KKGB. Later on, a more detailed tectonic model for the KKGB, based on new aeromagnetic data and additional field structural analysis, was created by Henderson et al. (2015).

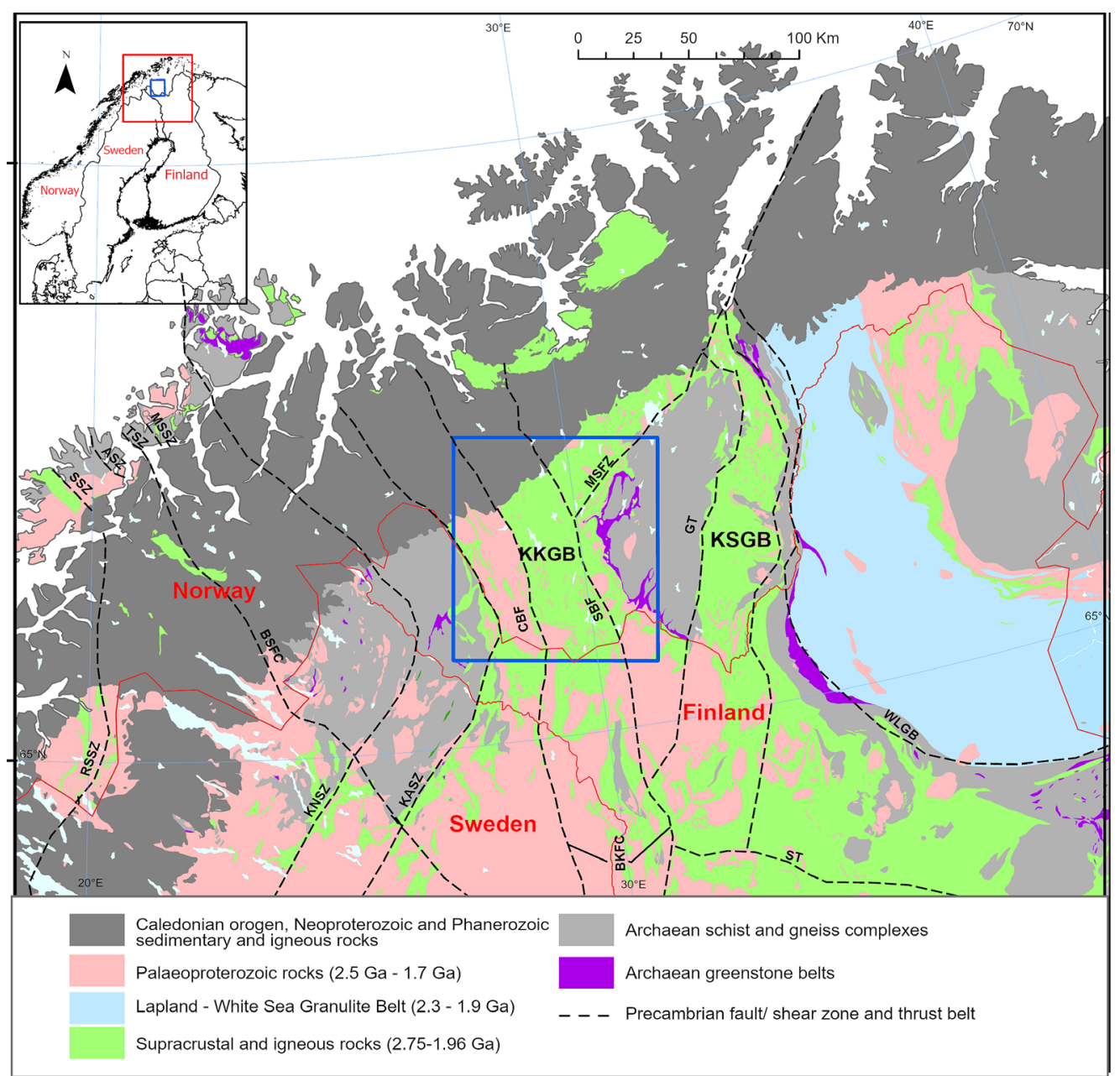

Figure 1. Tectonic map of northern Scandinavia (modified after Koistinen et al., 2001 )and the main structural trends of Palaeoproterozoicand Archaean basement areas in northern Finland, Norway and Sweden. The study area for the 3D model is shown by the blue box. ASZ: Astridal Shear Zone; BKFC: Botnian-Kvæenangen Fault Complex; BSFC: Bothnian-Senja Fault Complex; CBF: Čieknaljohka-Boaganjávri Fault; GT: Guvvajávri thrust; KASZ: KaresaundoArjeplog Shear Zone; KKGB: Kautokeino Greenstone Belt; KNSZ: Kiruna-Naimakka Shear Zone; KSGB: Karasjok Greenstone Belt; MSFZ: Mierojávri-Svarholt Fault Zone; MSSZ:Mjelde-Skorelvvatn Shear Zone; RSSZ: Rombak-Skjomen Shear Zone; SBFZ: Soagnojávri-Bajášjávri Fault; SSZ: Svanfjellet Shear Zone; ST:Sirkka Line; TSZ: Torsnes Shear Zone; WLGB: Western margin of Lapland Granulite Belt. 
The Kautokeino area constitutes the western part of Finnmarksvidda and has a rather smooth topography with an undulating relief between 350 and $650 \mathrm{~m}$ asl. Local mountain ridges, such as Davvi-Likča (828 m asl.), Čáravárri (887 m asl), Čáskejas-Albbasoaivi (770 m asl.) and Ságge-Čierte (852 $\mathrm{m}$ asl.), stand out on the plateau in the north. The Kautokeino-Masi area is to a large degree covered by Quaternary overburden. The number of bedrock exposures is highest in the north. The southernmost area towards the Finnish border is especially flat with poor drainage and large bogs.

In the present study, the KKGB has been analysed by integrating all available geophysical, geological and petrophysical data in combination with 3D density modelling into a consistent crustal-scale 3D structural model. The new high-resolution geophysical data and surface observations have been utilised to identify several new structural units that can help to improve the existing geological map of this region. The initial model area was extended to include the northern part of Finland and Sweden (Fig. 1) to provide better control on the regional setting of the KKGB and to reduce the border edge effects around the key study area. Karinen et al. (2015) have presented detailed 3D models for two areas in northern Finland. However, those areas are rather small compared with our study area.

\section{Geology of the Kautokeino Greenstone Belt}

The bedrock geology of northern Norway (Fig. 1) is dominated by complexes of Precambrian to Early Palaeozoic age, a large part of which was involved in the Caledonian orogeny. In general, there is a basic two-fold division of the study area into the Caledonides sensu stricto and a mid-crustal continental lithospheric basement comprising autochthonous and allochthonous crystalline complexes that range in age from Neoarchaean to Late Palaeoproterozoic, forming the northern part of the Fennoscandian Shield (Fig. 1; Gaál et al., 1989; Daly et al., 2006). These older Precambrian rocks are mainly observed in Finnmark and western Troms, and some are either affected locally by Caledonian deformation or incorporated as thrust slices in the Caledonian nappes (Figs. 1 \& 2).

The KKGB is subdivided into several formations. The Goldenvárri Formation (Solli, 1983) is oldest and consists of mafic volcanic rocks metamorphosed in amphibolite facies. They occur along the eastern margin of the KKGB. The Masi Formation lies above the Goldenvárri Formation with a supposed angular unconformity and consists mainly of quartzites. The bulk of the greenstone belt is occupied by the Čáskejas, Likčá and Suolovuopmi formations (Solli, 1983; Siedlecka et al., 1985; Olesen \& Sandstad, 1993) each of which consists mainly of basic metavolcanites (Fig. 2). The volcanic rocks are dominated by basic tuffs and tuffites, but basaltic lavas and concordant diabases are also present. In some places, komatiitic metavolcanites can be found. Mica schists interpreted as metamorphosed, fine-grained terrigenous sedimentary rocks are interbedded with the volcanites, but only in the Suolovuopmi Formation to the northeast do they make up a considerable portion of the rocks. The Suolovuopmi Formation in the Masi area is interpreted to have formed on a marine platform at a rift margin. The youngest rocks of the greenstone belt are found in the central northern parts. Here, it can be demonstrated that the volcanism in the Čáskejas Formation gradually decreased and that the formation is concordantly overlain by pelites (Bihkkačohkka Formation) and sandstones (Čáravárri Formation; Sandstad, 1983, 1985). According to Bergh \& Torske $(1986,1988)$ the Čáravárri Formation and the greenschist-facies volcanosedimentary rocks within the eastern part of the Čáskejas Formation were formed within the gradually subsiding Alta-Kautokeino Rift (AKR) along the margin of the Karelian continental block. Deformation and metamorphism are of low intensity in the central part of the KKGB and increase towards the gneiss complexes to the west and east, where the bedding and the foliation are generally steep. In the northeastern part of the KKGB the structural trend is NE-SW and the dip flattens out (Solli, 1988). 


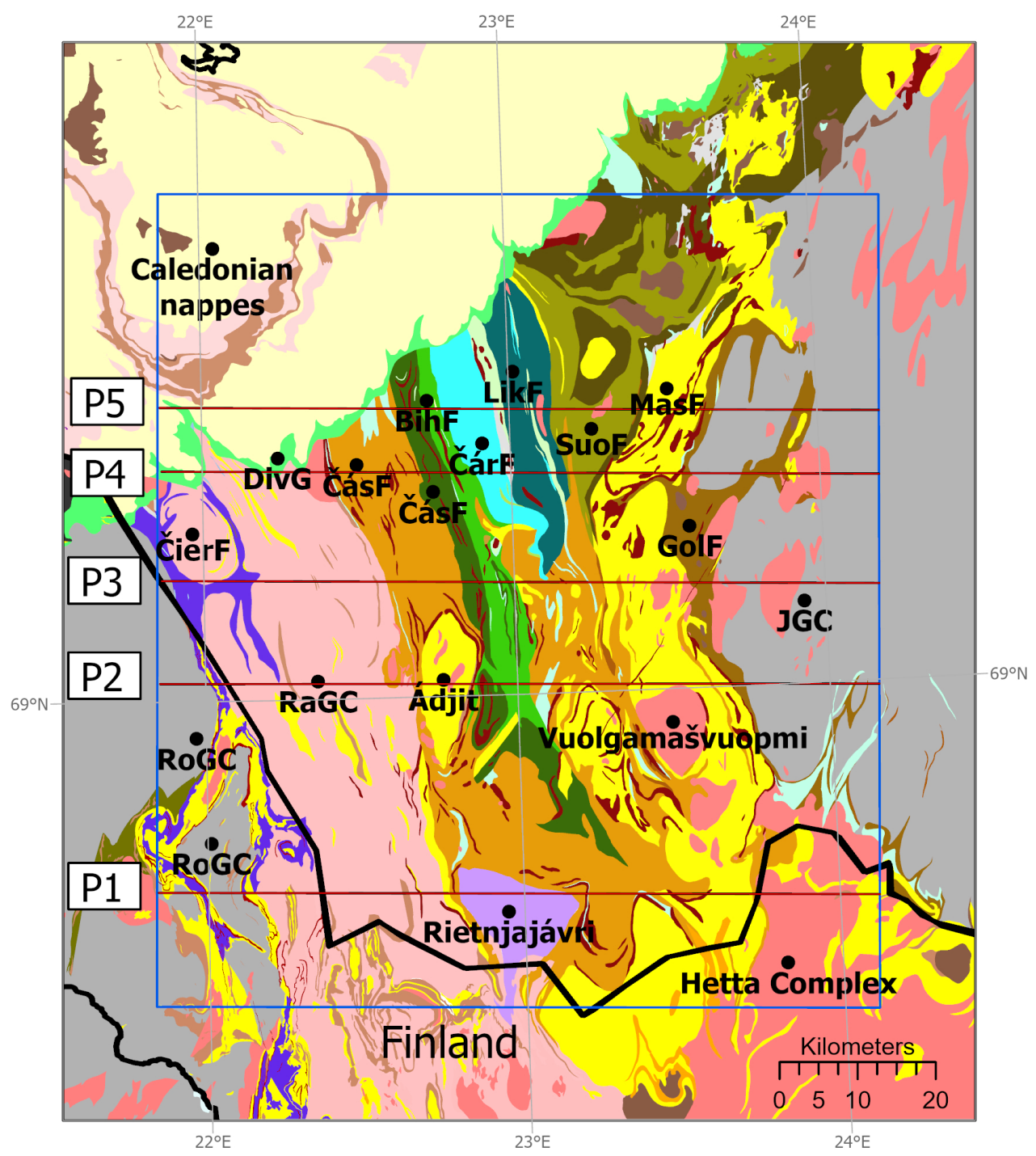

\section{Caledonian nappes}

Gabbro
Metasedimentary rocks: mainly arkose quartzite
Granodioritic gneiss
Amphibolite
Dividal Group
Intrusions
Granitoid plutons
Monzonite
Gabbro-diabase bodies (Diabase, Dolerite)
Intrusive rocks, predominantly mafic/ ultramafic
Kautokeino Greenstone Belt
Č́ravárri Formation: sandstone
Bihkkačohkka Formation: mainly argillite
Ráiseatnu Complex: gneiss-granitoid
Čáskejas Formation: mainly amphibolite
Č́skejas Formation: mainly greenstone
Njállajohka Complex and its Finnish extension : greenstone
Likčá Formation: greenstone
Suolovuopmi Formation: schist
Suolovuopmi Formation: mainly amphibolite
Masi Formation + related quartzite units
Goldenvári Formation: mainly amphibolite

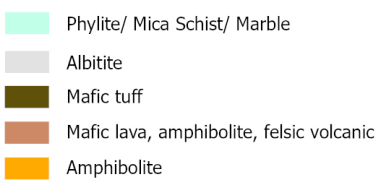

\section{Archaean Gneiss Complexes}

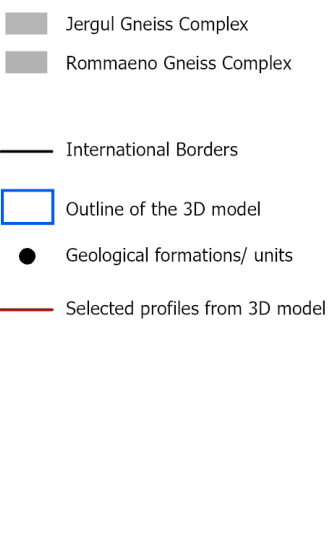

Figure 2. Bedrock geological map of the study area. The map is modified from the bedrock map of Norway at a scale of 1:250.000 (Olesen \& Sandstad 1993) and the bedrock map of Finland at a scale of 1:200.000 (Karinen et al., 2015). BihF= Bihkkačohkka Formation, ČárF= Čáravárri Formation, ČásF= Čáskejas Formation, ČierF= Čierte Formation, DivG= Dividal Group, GolF= Goldenvárri Formation, JGC= Jergul Gneiss Complex, LikF= Likčá Formation, MasF= Masi Formation, RaGC= Ráiseatnu Complex, RoGC= Rommaeno Gneiss Complex, SuoF= Suolovuopmi Formation. 
The Jergul Gneiss Complex is partly of Archaean age (Olsen \& Nilsen, 1985; Krill et al., 1985; Bingen et al., 2016) and forms the basement to the greenstone belt. However, no clear depositional contact has been found between the gneisses and the supracrustals, presumably since the contacts are either fault-bounded or have been obliterated by younger felsic intrusions.

The western area of the KKGB is dominated by NNW-SSE-trending faults mapped and interpreted by Sandstad (1985) and Olesen \& Solli (1985). Berthelsen \& Marker $(1986)$ and Henkel $(1988,1991)$ include these faults in the regional Baltic-Bothnian megashear and Bothnian-Seiland shear zone, respectively. We think that the name Botnian-Kvænangen Fault Complex, BKFC (Fig. 1), will be more appropriate since the zone can be traced from the Bay of Botnia to Kvænangen; and its continuation to the Baltic Sea in the south is poorly defined. The BKFC is composed of several fault segments which are well defined from both geological and geophysical data (Holmsen et al., 1957; Olesen \& Solli, 1985; Berthelsen \& Marker, 1986; Geol. Surveys of Finland, Norway and Sweden, 1986a, b, 1987; Henkel, 1991; Olesen et al., 1990; Olesen \& Sandstad, 1993). In the Kautokeino area, 3-4 regional NNW-SSE fault zones have been delineated (Olesen \& Solli 1985, Olesen et al., 1990, Olesen \& Sandstad, 1993). The steeply dipping structures, the Čieknaljohka-Boaganjávri Fault, $\mathrm{CBF}$, to the west and the Soagnojávri-Bajášjávri Fault, SBF, to the east constitute parts of the BKFC and are continuous along the entire KKGB. Along the $\mathrm{SBF}$ to the east, cross-cutting relationships to magnetic reference structures can be observed. A striking feature seen in Fig. 3 is the change in the magnetic pattern from NE-SW-trending structures $5 \mathrm{~km}$ north

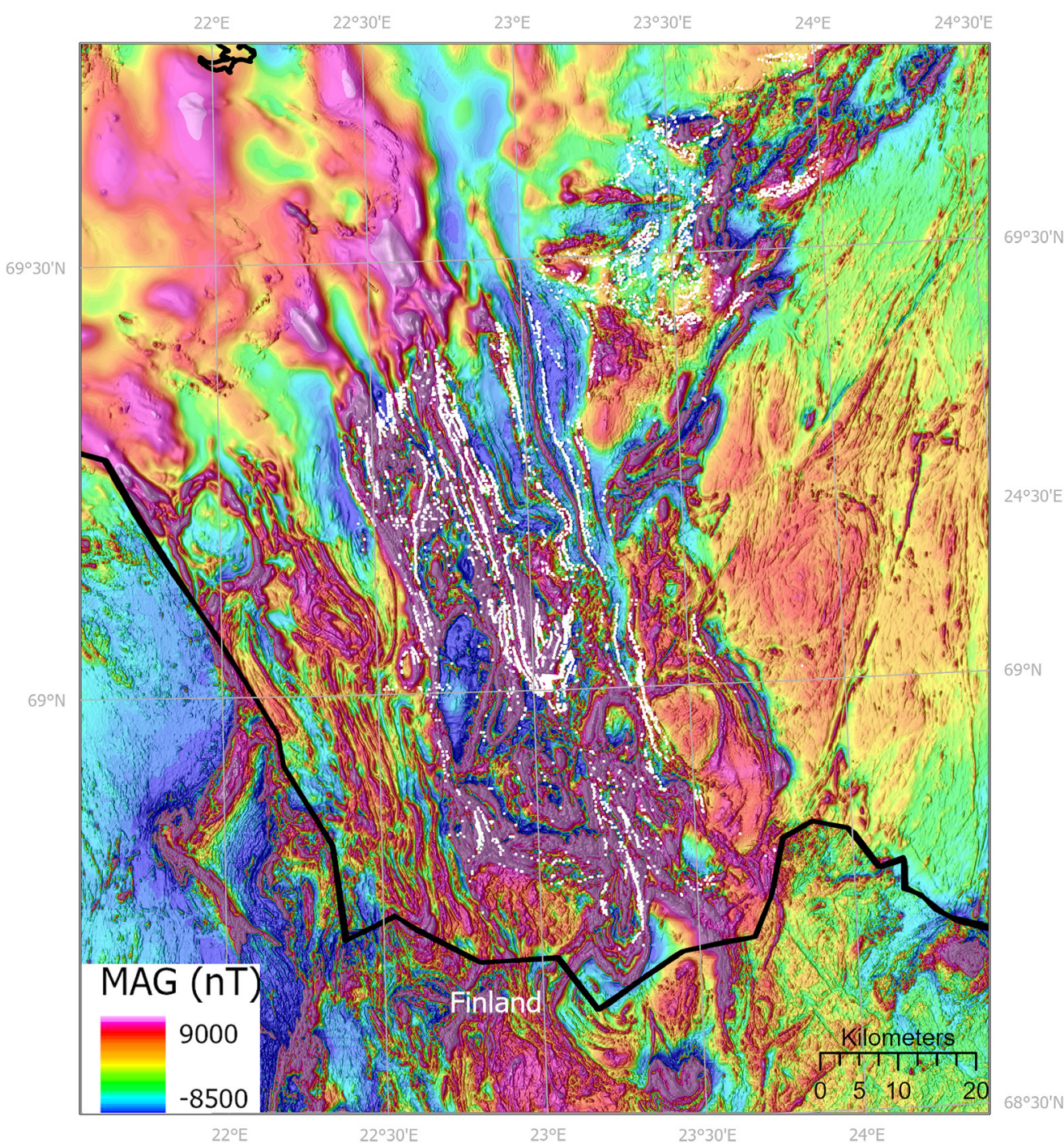

Figure 3. Compiled magnetic anomaly map over the study area. Data from different surveys in Norway (NGU) and adjacent parts of Finland (GTK) (Nasuti et al., 2015). The white dots show the electrical conductors (Olesen \& Sandstad, 1993). 
of Mierojávri to the NNW-SSE-trending structures at the margin of the BKFC. This indicates that the NE-SW structures are apparently transected by sinistral displacement along the SBF (Olesen \& Sandstad, 1993). Immediately to the south of the Caledonian front north of Soadnjujavri there is a similar discordance between the E-W-trending structures within the Suolovuopmi Formation and the N-Strending structures in the Likča Formation. Holmsen et al. (1957) reported N-S-trending faults with brecciation and mylonitisation of the rocks at both locations. Bjørlykke et al. (1993) and Henderson et al. (2015) have also observed structures ascribed to sinistral movements along shear zones within the BKFC.

Olesen et al. (1992), Olesen \& Sandstad (1993) and Henderson (2015) interpreted the regional Mierojávri-Sværholt Fault Zone (MSFZ) as the main border between the Jergul Gneiss Complex and the Goldenvárri Formation in the southeast and the more flat-lying Suolovuopmi Formation in the northwest. They observed a regional dextral displacement along the MSFZ and the related contractional Biggevárri duplex within the deformed and faulted Masi Formation. A reflection seismic profile (Ruud et al., 2021; Olesen et al., 2021) shows that the c. $5 \mathrm{~km}$-wide MSFZ is dipping at an angle of c. $45^{\circ}$ below the Jergul Gneiss Complex.

\section{Data}

Multidisciplinary geophysical datasets are available for most of the study area. Parts of the area under consideration, however, are characterised by a lack of electromagnetic data. The existing radiometric data are of varying vintage and quality.

\section{Aeromagnetic data}

The Geological Survey of Norway (NGU) has conducted aeromagnetic surveys on the Norwegian mainland and continental shelf since 1959 (Olesen et al., 2010) and, up to present day, the entire country has been covered by aeromagnetic data. In the Kautokeino area, aeromagnetic and electromagnetic data have already been applied to investigate the greenstone belts (Olesen \& Solli, 1985; Olesen et al., 1990; Olesen \& Sandstad, 1993; Henderson et al., 2015). However, due to inaccurate correction of diurnal artefacts, navigation errors and poor resolution of some of the vintage magnetic data, acquired in the 1960s and early 1970s in northernmost Norway, the corresponding magnetic dataset (e.g., Skilbrei et al., 1991; Olesen et al., 2010) has a relatively low resolution and poor quality. Besides, the vintage aeromagnetic grid was partly based on digitised hand-contoured maps. The Proterozoic greenstone belts were covered with helicopter-borne magnetic, electromagnetic and radiometric surveys in 1974-1991 (Olesen \& Sandstad, 1993). In 2011, the decision was made to remap the remaining parts of the Finnmark region with state-of-the-art, high-resolution aeromagnetic data in order to update and replace the remaining vintage magnetic datasets (Figs. $3 \& 6$ ). The new surveys were carried out during the summers of 2011, 2012 and 2014 (Nasuti et al., 2015) and consist of the Finnmark Region Airborne Survey (FRAS-11) (Novatem 2012) and Troms $\varnothing$-Finnmark Airborne Survey (TROFI-12). Some parts of the study area were also covered by high-resolution helicopter-borne surveys with denser line spacing and lower flight height. Moreover, the newly acquired data together with older data from 1979-91 have been reprocessed and significantly improved using a new software and levelling system (Geosoft, 2010). In addition to the Norwegian database, we have included parts of the adjacent aeromagnetic data from the Geological Survey of Sweden (SGU) and the Geological Survey of Finland (GTK) (Airo, 2005; Moore, 2008). This allowed us to trace the continuation of geological structures across international borders. The final compiled data are shown in Fig. 3 . The differences in the data resolution of the surveys are clearly visible in the composite map. These differences are caused 
either by variable line spacing or by the varying altitude of the aircraft for the data acquisition within each survey area. Not surprisingly, lower ground clearance, steeper climb/descent rate and tighter line spacing provide higher resolution data. We have not applied a direct upward or downward continuation of the datasets because the main purpose has been to show the optimal resolution of the data.

\section{Gravity data}

A regional gravity survey was carried out on Finnmarksvidda within the Finnmark Programme during 1980-1988 (Olesen \& Solli, 1985; Olesen et al., 1993), mostly using snow scooters and helicopters for transportation. Measurements were made at stations located $1-4 \mathrm{~km}$ apart (Fig. 4). The complete Bouguer reduction (Mathisen, 1976) of the gravity data has been computed using a rock density of $2,670 \mathrm{~kg} / \mathrm{m}^{3}$, the International Gravity Standardization Net 1971 (I.G.S.N. 71) and the Gravity Formula 1980 for normal gravity. Besides those data, NGU has measured additional gravity stations especially on the Ádjit structure to the west of the Kautokeino village. In addition to the Norwegian gravity database, we have also used parts of the SGU and GTK regional gravity data (Fig. 4).

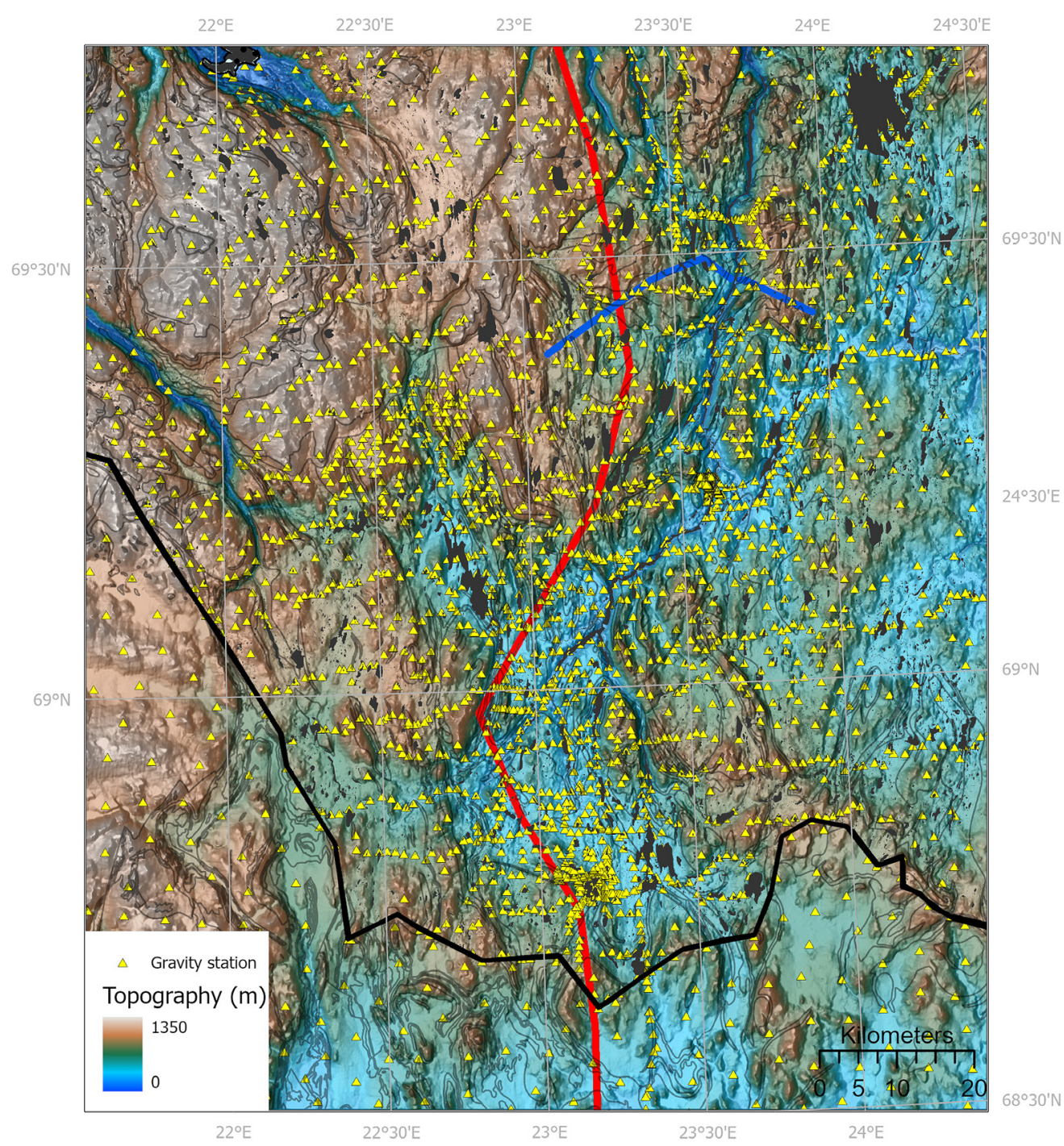

Figure 4. Topographic map of the study area (www.hoydedata.no). The measured gravity points are shown by the yellow triangles. The red line shows the FENNOLORA seismic line (Guggisberg et al., 1991), and blue line shows the Masi reflection seismic line (Mrope et al. 2019; Olesen et al. in press, Ruud et al. 2021). 


\section{Petrophysical data}

NGU has carried out petrophysical sampling programmes (including density, susceptibility and remanence measurements) to assist the bedrock mapping and mineral exploration programmes in mainland Norway. In addition, density measurements have been carried out on bedrock samples in conjunction with gravity campaigns. The measured values have been recorded in the NGUs petrophysical database (Olesen et al. 1993). Approximately 1100 rock samples were collected during geological mapping and geophysical studies and their density, magnetic susceptibility and remanence were measured at the NGU laboratory (Olesen \& Sandstad, 1993). Fig. 5 shows the measured densities of rock samples using coloured symbols. Regionally non-representative samples (e.g., sulphide mineralisations, hydrothermal alterations, mylonites, diabases) were removed from the final dataset, shown on this map. In addition to the NGU petrophysical measurements, the presented map shows the petrophysical measurements from Finland provided by GTK. The rock samples are not distributed uniformly within the study area. One reason behind this is that Finnmarksvidda is heavily covered by Quaternary deposits and vegetation overburden with very limited bedrock exposure in the area. Therefore, it was difficult to extract the rock samples. The measured densities are averaged over the different rock units and formations and used for constraining the constructed 3D model (see Table 1).

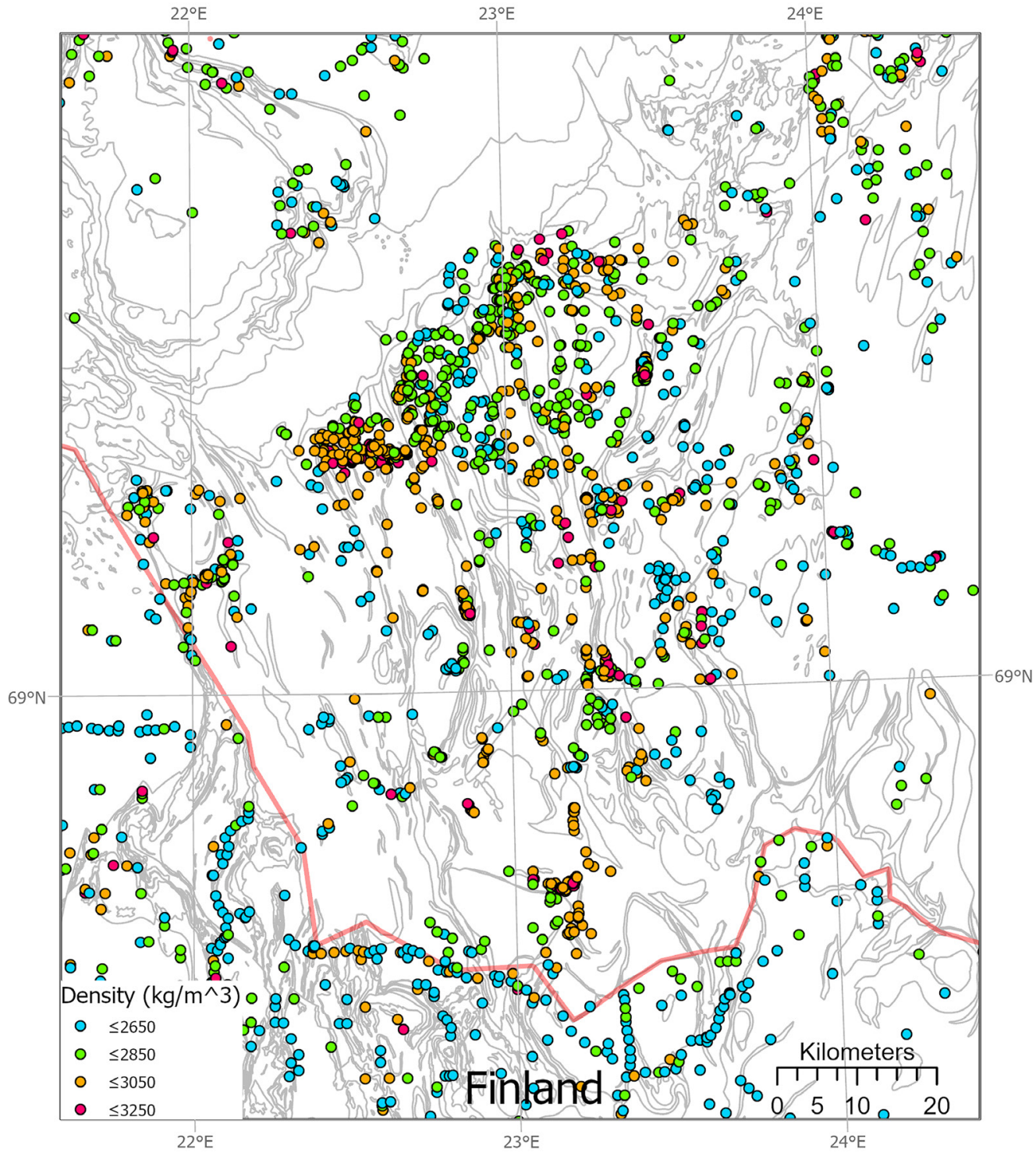

Figure 5. Density measurements $(\mathrm{kg} / \mathrm{m3})$ within the study area. Data from NGU and GTK. 
Table 1. Densities, assigned to crustal blocks/layers and mantle for the 3D model. Colours are the same as used for visualisation of the IGMAS model in Figs. 14-20.

\begin{tabular}{|c|c|c|}
\hline Colour & Layer, formation, or Rock unit & $\begin{array}{c}\text { Average density } \\
\left(\mathrm{kg} / \mathrm{m}^{3}\right)\end{array}$ \\
\hline & Upper crust (Jergul and Ráiseatnu gneiss complex) & 2670 \\
\hline & Upper crust (intermediate rocks) & 2800 \\
\hline & Middle crust & 2850 \\
\hline & Lower crust & 3085 \\
\hline & Mantle & 3300 \\
\hline & Goldenvárri Formation & 2970 \\
\hline & Čáskejas Formation (amphibolite facies) & 2960 \\
\hline & Čáskejas Formation (greenschist)facies & 2860 \\
\hline & Suolovuopmi Formation & 2900 \\
\hline & Likčá Formation & 2830 \\
\hline & Bihkkačohkka Formation & 2730 \\
\hline & Čierte Formation (Njállajohka or Finnish greenstone) & 2950 \\
\hline & Migmatised Ráiseatnu & 2800 \\
\hline & Čáravárri Formation & 2630 \\
\hline & Masi Formation & 2640 \\
\hline & Monzonite & 2750 \\
\hline & Granodiorite & 2630 \\
\hline & Granite & 2610 \\
\hline
\end{tabular}

\section{Radiometric data}

Airborne measurements of gamma-rays emitted from unstable isotopes of natural radioactive elements (e.g., $\mathrm{K}, \mathrm{U}$ and $\mathrm{Th}$ ) are used to calculate the equivalent concentration of these radioelements in soil and rocks within the upper $30-50 \mathrm{~cm}$ of the subsurface. Potassium is a major component comprising $2.35 \%$ of the Earth's crust and is commonly found in K-feldspars and micas. Uranium and thorium are minor components comprising 3 and $\sim 12$ ppm of the Earth's crust, respectively (Dickson \& Scott, 1997; IAEA, 2003). Uranium occurs in rocks as U-oxide, U-silicate, uraninite, uranothorite, monazite, xenotime and zircon. Thorium occurs in allanite, monazite, xenotime and zircon. In general, the radioelement concentrations increase with an increasing Si content.

Vintage NGU helicopter-borne radiometric data from the Kautokeino area were acquired during 1979-1991 (Nasuti et al., 2015). New airborne surveys (helicopter and fixed-wing) were collected through the Minerals in North Norway (MINN) programme (Fig. 6). All the vintage radiometric data were reprocessed and stitched together to produce a complete compilation of uranium (U), thorium (Th) and potassium (K) maps for Finnmark. 


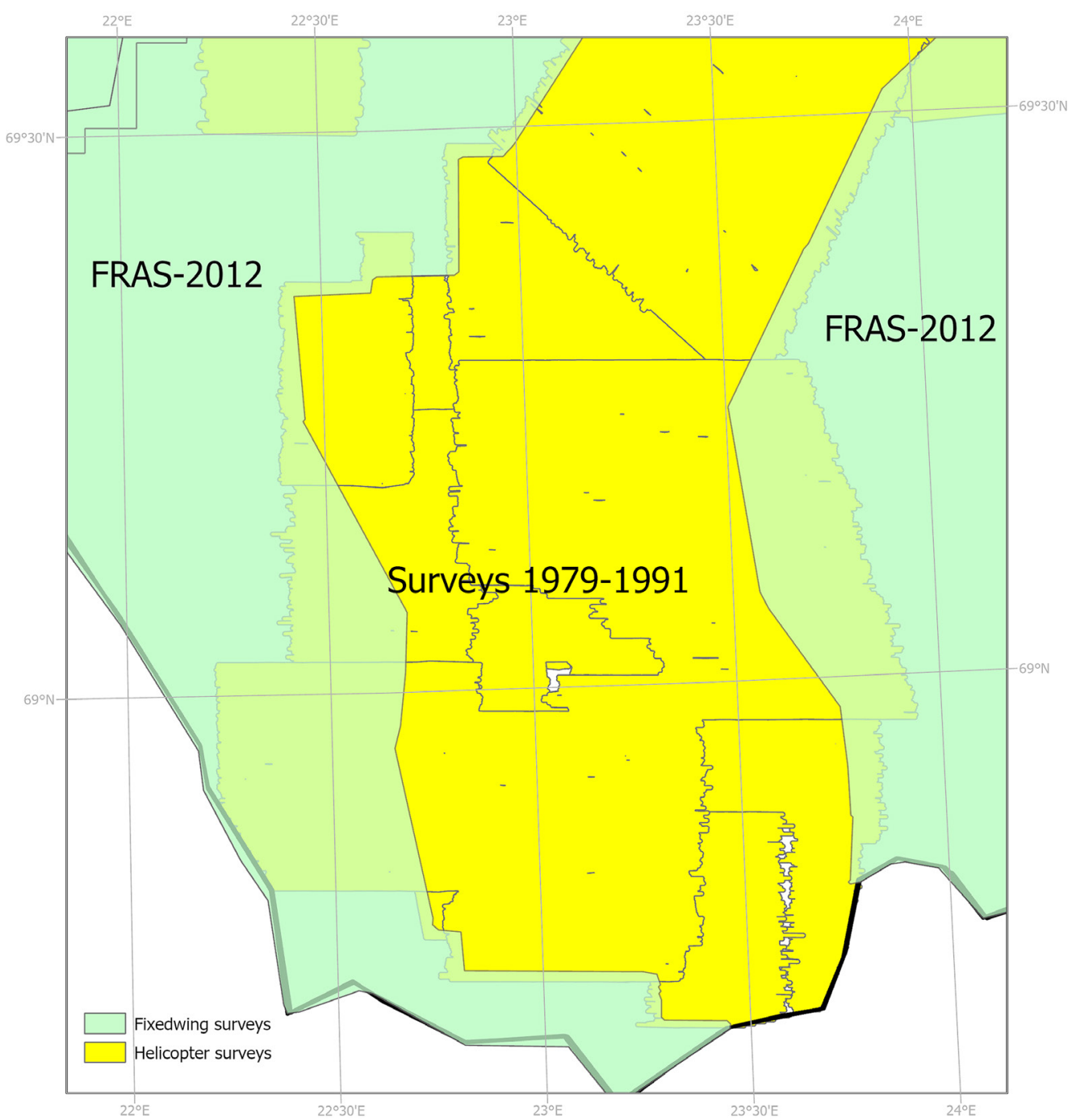

Figure 6. The location of the radiometric surveys outlined by the coloured polygons. More details can be found in Nasuti et al. (2015).

The vintage data existed in counts per seconds (cps) units and had significant variations in the data quality (Nasuti et al., 2015). The quality of the $\mathrm{K}$ and Th data was better than the $\mathrm{U}$ data. $\mathrm{U}$ data were very noisy for most of the vintage surveys. After levelling, low pass filtering and gridding at greater grid intervals were applied to reduce the random noise from the $\mathrm{U}, \mathrm{Th}$ and $\mathrm{K}$ data. This strategy worked for most of the surveys except for U in Kautokeino's 1985 survey (Mogaard \& Skilbrei, 1986), where only the strong $\mathrm{U}$ anomalies were trustworthy due to very poor data quality. The vintage radiometric $U, T h$ and $\mathrm{K}$ grids were then stitched to generate single grids using a combination of GridKnit by Geosoft (Oasis montaj 2010) and an improved version of histogram matching algorithm by Cowan \& Cooper (2008).

The data quality of the fixed-wing survey from the MINN programme (FRAS-12) was excellent, and no further adjustments were needed. The ground concentrations from the Repparfjord area (Ofstad et al., 2013) were used as a base for calculating the ground concentrations from older uncalibrated vintage data (in cps) using the histogram matching algorithm. Overlapping areas were used in the histogram matching scheme to define a relation between the histograms of the two grids considering FRAS-12 as a reference and modifying the other grid and subsequently merging them using the GridKnit module. This process was repeated from one to the other overlapping grids until the complete compilation of the Finnmark area was achieved. 


\section{Electromagnetic data}

Electromagnetic data were collected during 1979-1991 using a Sander EM-3 coaxial coils system at $1000 \mathrm{~Hz}$ frequency by hanging it c. 100 feet below the helicopter (Olesen \& Sandstad, 1993). Discrete electromagnetic responses were analysed to map conductors using the vertical sheet model. The conductance (i.e., conductivity-thickness product) in $\mathrm{ohm}^{-1}$ (mho) of the vertical sheet model was calculated regardless of the interpreted geometric shape of the conductor. Strong conductors are characteristic of graphite or massive sulphides. Conductors with conductance higher than 5 mhos are plotted in Fig. 4. Graphite schists commonly coincide with shear zones in the KKGB because of the lubrication effect of the graphite.

\section{Seismic profiles}

There is a vintage and large-scale N-S-trending refraction seismic line FENNOLORA (Guggisberg et al., 1991) crossing the study area and a shorter, $24 \mathrm{~km}$-long, E-W-trending reflection seismic profile in the Masi area to the northeast within the study area (Mrope et al., 2019; Ruud et al., 2021; Olesen et al., 2021). While the FENNOLORA seismic profile does not provide details, it is valuable for constraining the regional trend of the Moho depth within the study area that is described later in more detail (see the location in Fig. 4).

\section{Results from mapping analysis}

\section{Gravity and magnetic anomalies and their links to geological features in the study area.}

Similarities and differences in the gravity and magnetic surveys can be used to extract valuable information about geological features both at the surface and at depth. In this regard, it is crucial to consider the resolution of these datasets. In this chapter, several maps are presented. The earlier measured gravity and more recently acquired aeromagnetic data from the region are analysed to provide information about the geological features in 3D.

Considering the location of the stations and the way that they are spread out in the region (Fig. 4), one can conclude that gravity data (Fig. 7A) can only be used to study the regional to medium-sized structures, except for some profiles along relatively densely located stations. The denser spaced stations are located along the main roads of the region and along $\mathrm{E}-\mathrm{W}$-trending snow-scooter profiles. To study the geological features with a size less than 1-2 km, additional gravity data should be acquired. The overall gravity anomaly map shows higher values in the south and to the east of the study area and gradually decreasing to the west and north, where Caledonian rocks are overlying the Precambrian bedrock. Applying a vertical derivative filter (VD, Fig. 7B) and tilt derivative (Miller \& Singh 1994, Fig. 7C) helps to enhance more local features in the gravity data. Fig. 7B shows the superimposed geological boundaries (1:250,000 scale) on the vertical derivative gravity map. There is a visible correlation between the large geological rock units and the gravity map since the Bouguer gravity anomaly of the study area is dominated by the high-density rocks of the greenstone belts of Norway and adjacent parts of Finland. Fig. 7D shows the positive values from the tilt derivative. The tilt derivative is a normalised filter that enhances both shallow and deeper sources by putting them at the same level (magnitude). The vertical derivative map shows the shallower anomalies with higher amplitudes. The 1st VD has no directional bias, which is a key characteristic in improving the spatial and structural resolution of the imagery. 

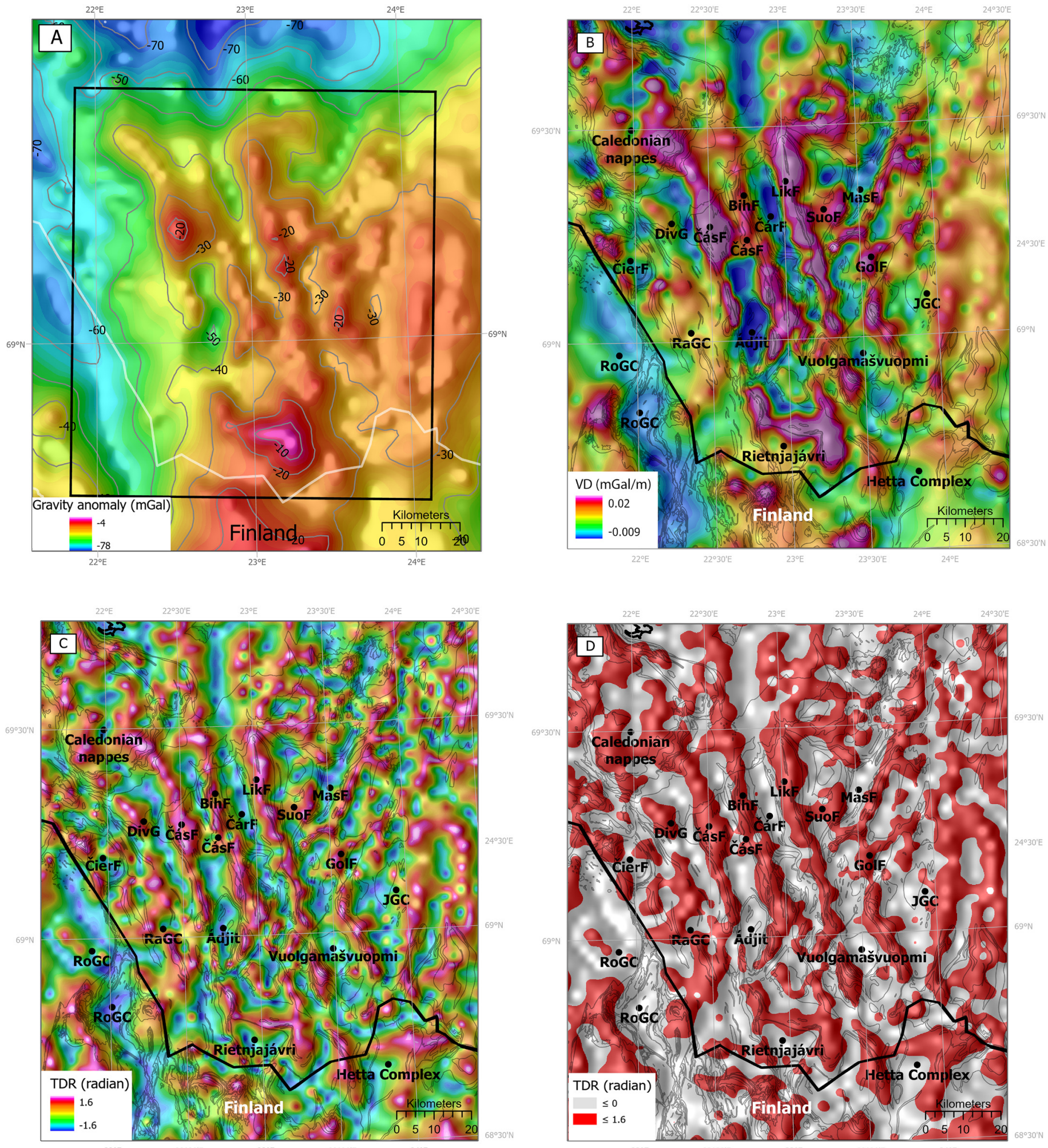

Figure 7. Gravity anomalies. (A) Bouguer gravity anomalies over the study area. Compiled from NGU and GTK data. The black frame outlines the area covered by the 3D model. (B) The first vertical derivative of gravity data. (C) Tilt derivative of a vertical derivative of gravity data. (D) Positive tilt derivative values. BihF=Bihkkačohkka Formation, ČárF= Čáravárri Formation, ČásF= Čáskejas Formation, ČierF= Čierte Formation, DivG= Dividal Group, GolF= Goldenvárri Formation, JGC= Jergul Gneiss Complex, LikF= Likčá Formation, MasF= Masi Formation, RaGC= Ráiseatnu Complex, RoGC= Rommaeno Gneiss Complex, SuoF= Suolovuopmi Formation. 
The 1st VD map, shown in Fig. 7B, depicts several distinct anomalies. The gravity lows coincide either with granitic intrusions or sedimentary rocks (e.g., Masi quartzite and Čáravárri sandstone formations). Some of these anomalies are elongated and parallel to the denser rock units of metavolcanic rocks. For example, the low gravity anomaly over the Čaravarri sandstone formation has an extension southward in relation to what is shown on the geological maps (Solli, 1990; Olesen \& Sandstad, 1993), as well as the low gravity anomalies related to some exposed granitic bodies can be extended compared to the previously mapped structures which are exposed at the surface. The high gravity anomalies in the Jergul and Ráiseatnu gneiss complexes are subdued; however, those areas are also characterised by the presence of a set of high-frequency anomalies (Figs. 7C \& 7D) also discussed by Olesen \& Solli (1985). These two areas are heavily covered by Quaternary overburden and have not been mapped at a scale of 1:50,000 like the greenstone belt areas. However, it must also be mentioned that those areas are less covered with gravity stations (Fig. 5). Fig. 7D highlights the dense rocks of the region using positive values of the tilt derivative. Noteworthy, the resolution of data plays an important role in identifying the dense volcanic rocks. For example, although geological maps (Figs. 1 \& 2) show dense volcanic rocks to the west of the Ráiseatnu Gneiss Complex in Finland, the gravity anomaly data are not able to detect them most likely due to sparsely located gravity stations in that area. It is also possible that the thickness of these rock units is too small to be detected with the existing regional gravitational dataset.

In contrast to the gravity data, the aeromagnetic data have a higher resolution which enables us to delineate very fine details of the structural features within the study area. Fig. 8A shows the reduced to pole (RTP) magnetic anomaly. RTP conversion is used to facilitate the interpretation, which theoretically will remove the dipole effects inherited in magnetic data. There is no large difference between the original magnetic anomaly (Fig. 3) and its RTP transformation (Fig. 8A) since our study area is located at high latitudes.

The magnetic anomaly map comprises very high (positive) and low (negative) anomalies. Comparing the geological (Fig. 2) and first vertical derivative of magnetic data (Fig. 8B) reveals that most of the high-amplitude magnetic anomalies are caused either by diabase (dolerite) dykes or metavolcanic rocks (amphibolites and greenstones) of the greenstone belt. Very shallow anomalies are highlighted in Fig. 8B, making it easy to recognise them on original magnetic data. The map also shows their potential exposures at the surface. The analytical signal (Nabighian 1972, 1984) points to a fundamental difference between the Jergul, Rommaeno and Ráiseatnu gneiss complexes within the study area. Both Jergul and Rommaeno gneiss complexes (JGC and RoGC) show relatively few linear features and rounded magnetic features. These gneiss complexes are mostly without strong magnetic anomalies, whereas the Ráiseatnu Gneiss Complex (RaGC) has very distinctive linear and large rounded anomalies (caused by deformed volcanosedimentary units, dykes and shear zones). The positive magnetic anomalies inside the RaGC are very similar to magnetic anomalies from the bedrock units of the eastern parts of the KKGB but with either lower amplitudes or a smaller number of anomalies. This difference in magnetic anomaly pattern was also pointed out by Olesen \& Sandstad (1993) and Henderson et al. (2015).

The analytical signal map (Fig. 8C), which is calculated from a combination of horizontal and vertical gradients of the magnetic anomalies (Nabighian 1972; Blakely, 1996), is capable to detect the shallowest edges of a magnetic body irrespective of the orientation of the body's magnetisation. The analytic signal effectively outlines these edge locations even in the presence of remnant magnetisation. Therefore, the analytic signal is considered as one of the most powerful tools in aeromagnetic investigations. However, the analytic signal loses its effectiveness when the depth to the magnetic rock body begins to approach its lateral dimensions (Isles \& Rankin, 2013). Grant (1985a, 1985b) showed that the magnetic susceptibility is reduced during a migmatisation process. Therefore, to enhance all the magnetic anomalies regardless of their depth, the tilt-derivative map is implemented (Fig. 8D). 

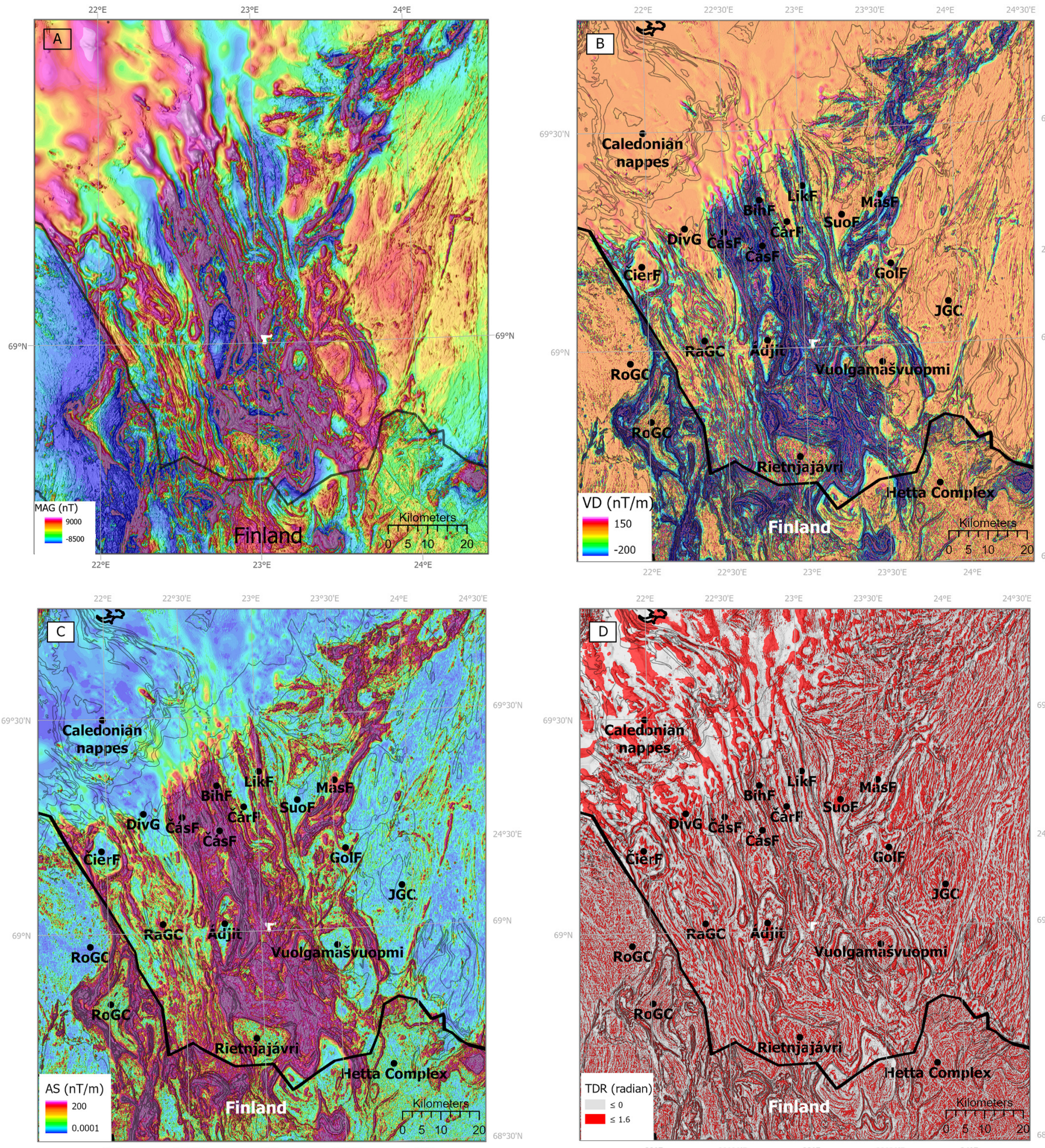

Figure 8. Magnetic anomaly maps. (A) Reduced to pole magnetic data (RTP). Data compiled from NGU and GTK. (B) The first vertical derivative of the aeromagnetic data. (C) Analytical signal of magnetic data. (D) Positive tilt derivative values of the magnetic data. Bih F= Bihkkačohkka Formation, ČárF= Čáravárri Formation, ČásF = Čáskejas Formation, ČierF= Čierte Formation, DivG= Dividal Group, GolF= Goldenvárri Formation, JGC= Jergul Gneiss Complex, LikF= Likčá Formation, MasF= Masi Formation, RaGC= Ráiseatnu Complex, RoGC= Rommaeno Gneiss Complex, SuoF= Suolovuopmi Formation.

Using the tilt derivative enables us to extract not only all the lineaments and enhance different magnetic sources but also to trace the greenstone belts beneath the Caledonian rocks, which are mostly magnetically transparent (compare Figs. 2 \& 8D). The increasing thickness of those Caledonian rocks to the north diminish the magnetic response from metavolcanosedimentary rocks of the KKGB . 

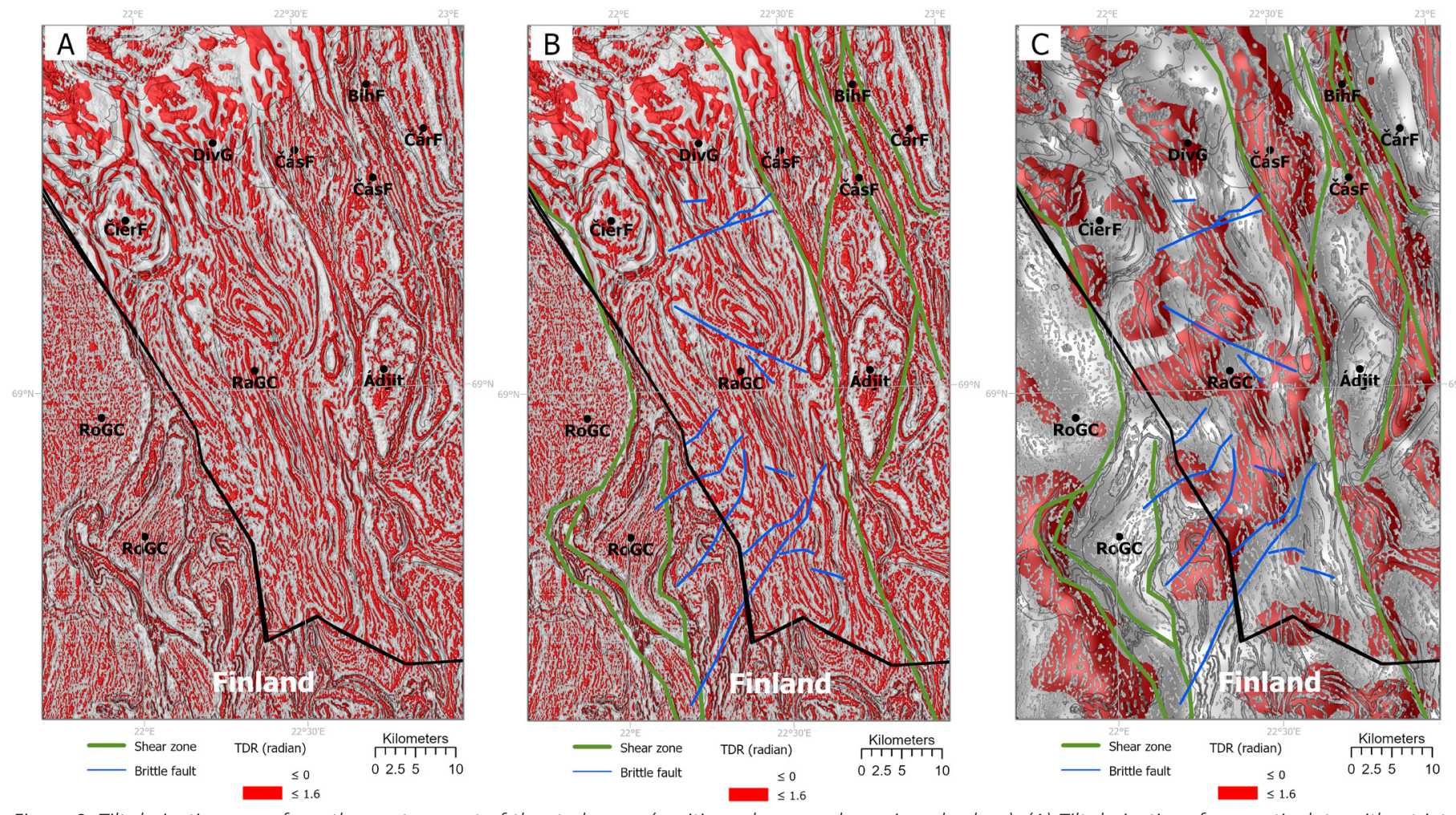

Figure 9. Tilt derivative maps from the western part of the study area (positive values are shown in red colour). (A) Tilt derivative of magnetic data without interpretations. (B) Tilt derivative of magnetic data with interpreted faults and shear-zones. (C) Positive values of tilt derivative from magnetic data overlaid on the gravity tilt derivative. BihF= Bihkkačohkka Formation, ČárF= Čáravárri Formation, ČásF= Čáskejas Formation, ČierF= Čierte Formation, DivG= Dividal Group, RaGC=Ráiseatnu Gneiss Complex, RoGC= Rommaeno Gneiss Complex.

Fig. 9 shows a detailed map of the western part of the study area. Henderson et al. (2015) have discussed the shear zones within the main part of the KKGB. Some of those shear zones are depicted in Figs. 9B \& 9C. Besides, by analysing the magnetic map (Fig. 8D), several dislocations can be recognised and interpreted within the Ráiseatnu Gneiss Complex based on observed displacements of reference structures and linear gradients. The long dislocations, subparallel to the magnetic anomalies, are most likely representing shear zones, whereas the shorter dislocations, cutting the magnetic banding at a higher angle, may represent younger and possible brittle to semi-ductile faults. The most pronounced NE-SW-trending dislocation is located in the southwest and extends from Finland to the southwest of the Ádjit dome (with potential granitic intrusions). The interpreted fault has a length of at least 30 $\mathrm{km}$. There are also several both small and large fault zones between the Ádjit dome and the Čierte greenstone formation (Fig. 9B).

Two of these faults border an area with circular magnetic anomalies (a group of positive and negative circular magnetic bands).

This structure is likely the folded one which has been deformed mostly due to the shearing. Using the observed similarity between the magnetic lineaments from the KKGB and the RaGC, we can recognise additional shear zones that are, however, not shown here. Fig. $9 \mathrm{C}$ shows the superimposed magnetic anomalies over the gravity positive anomalies. This figure reveals areas with denser rocks which most likely represent migmatised metavolcanites/amphibolites in the western part of the KKGB extending to the Čierte greenstone formation to the west at the RoGC margin.

Noteworthy, the rounded structure mentioned previously and located to the northwest of Ádjit, coincides with a positive gravity anomaly. Obviously, the resolution of gravity data is lower than for the magnetic data. We are, therefore, not able to detect the small faults discussed previously 
(located to the southwest in Fig. 9). These potential brittle faults may be caused by structural movements along the major shear zones to the east and west of the RaGC.

The NE-SW faults within the RaGC have a trend similar to the Mierojávri-Sværholt Fault Zone (MSFZ) and the JGC faults. Olesen \& Sandstad (1993) suggested that the structures of the MSFZ are continuous with the Karesuando-Arjeplog Shear Zone (KASZ) mapped by Henkel (1991). Fig. 10 shows regionalscale maps of gravity and magnetic data and vague indications of a possible connection between the two structures. Abundant dyke swarms (partly albite diabases) can be recognised as positive mangetic anomalies along both structures. It is notable that the KASZ in the southwest and the MSFZ in the northeast border large positive gravity and magnetic anomalies. During the 3D modelling, a longwavelength anomaly of the gravity field can be potentially bounded by a large and deep fault zone. However, if we accept such a hypothesis, there cannot be a large, accumulated displacement along the Bothnian-Kvænangen Fault Complex (BKFC). The magnetic data show, however, clearly that a young sinistral deformation occurred along the eastern margin of the latter structure (Olesen \& Sandstad 1993). They suggested that the MSFZ and the KASZ have an apparent sinistral offset of $10-15 \mathrm{~km}$ along the BKFC. We cannot, however, exclude an older dextral movement along the BKFC.
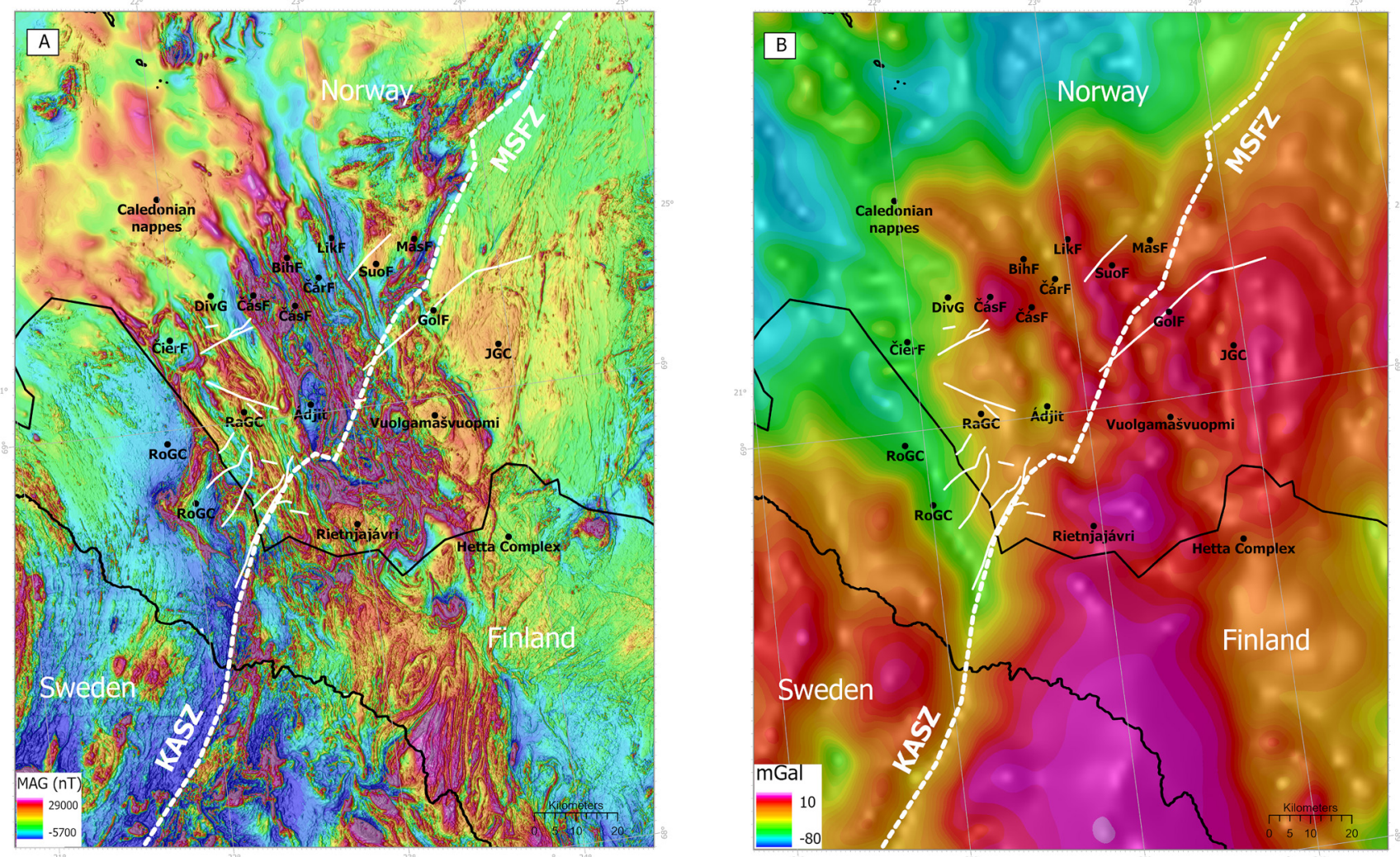

Figure 10. Regional magnetic (A) and gravity (B) maps. Interpreted faults are shown by the solid white lines. The bold dashed white line shows a questionable connection between the Mierojávri -Svarholt Fault Zone (MSFZ) and the Karesuando-Arjeplog Shear Zone (KASZ). BihF= Bihkkačohkka Formation, ČárF= Čáravárri Formation, ČásF=Čáskejas Formation, ČierF=Čierte Formation, DivG= Dividal Group, GolF= Goldenvárri Formation, JGC= Jergul Gneiss Complex, LikF= Likčá Formation, MasF= Masi Formation, RaGC= Ráiseatnu Complex, RoGC=Rommaeno Gneiss Complex, SuoF= Suolovuopmi Formation. 


\section{Results from radiometric data}

The obtained results from reprocessed radiometric data within the study region are shown in Fig. 11. The reprocessed data are characterised by a significant improvement compared with the previously published data (Nasuti et al., 2015). As we expected, the main KKGB region, which comprises mainly mafic and ultramafic rocks, is reflected by very low radiometric concentrations.
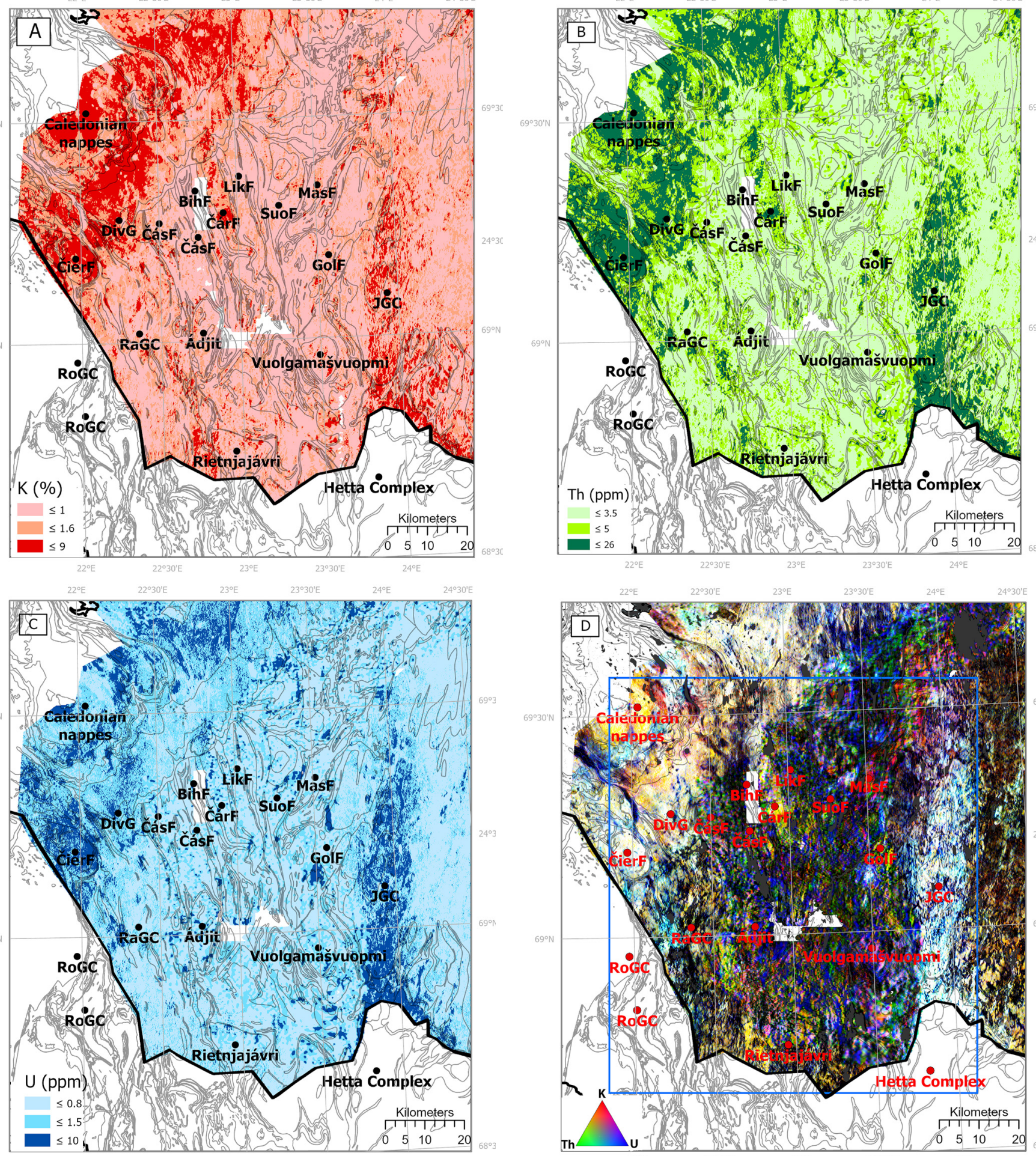

Figure 11. Radiometry data. (A) Potassium concentration (\%). (B) Thorium (ppm). (C) Uranium (ppm). (D) Ternary map consisting of potassium (red), uranium (blue) and thorium (green). The blue frame outlines the 3D modelled area. BihF= Bihkkačohkka Formation, ČárF= Čáravárri Formation, ČásF= Čáskejas Formation, ČierF= Čierte Formation, DivG= Dividal Group, GolF= Goldenvárri Formation, JGC= Jergul Gneiss Complex, LikF= Likčá Formation, MasF= Masi Formation, RaGC $=$ Ráiseatnu Complex, RoGC= Rommaeno Gneiss Complex, SuoF=Suolovuopmi Formation. 
However, based on the same data, areas with a high concentration of radiometric elements $(\mathrm{K}, \mathrm{Th}, \mathrm{U})$ are represented mainly by granitic rocks. For instance, the granitic region in the western JGC seems to be larger in these maps and it is most likely connected to the larger granitic intrusions that extend northwards from the Hetta Complex in Finland (see Fig. 2 and Fig 11D). Comparing the greenstone area to the south of Čierte with the western part of JGC suggests a presence of previously unmapped amphibolitic rocks. The ternary map (Fig. 11D) highlights the feldspar-rich areas such as the Čáravárri Formation (feldspar-bearing sandstones) with high $\mathrm{K}$ and Th concentrations. On the other hand, these areas are low in $U$ that makes them distinguishable from granitic areas. These regions are depicted in a yellowish colour, as a result of a combination of green and red, due to a presence of the relatively high concentrations of $\mathrm{K}$ (red) and Th (green) (Fig. 11D). We also see some patches of blue in Fig. 11D. However, these areas are characterised by the low concentration of $U$ (Fig. 11C). Unfortunately, these localities have noisy $U$ data that could not be properly cleaned and was only suppressed in Fig. 11C by the chosen colour scale. Another example is the western part of Rietnjajávri which is high in $\mathrm{K}$ and Th but it is characterised by a low $U$ concentration.

The radiometric data clearly confirm that both the RaGC and the JGC are more complex than those shown on the published geological maps. Therefore, these regions must be reconsidered for a careful re-mapping with an extensive use of the geophysical data.

The metasandstones within the Caledonian nappes have a quite high content of radiometric elements.

\section{D Modelling}

\section{Methodology of density and magnetic modelling}

The potential field modelling has been used to understand the 3D spatial distribution of the geological units which have been previously mapped at the Earth's surface. Particularly, the 3D density modelling has been carried out mainly to understand the large-scale configura-tion of the crystalline crust within the study area. During the 3D density modelling, the crys-talline crust of the study area has been subdivided into several crustal blocks according to similarities in densities and magnetic susceptibilities. In the current model, magnetic data have not been modelled but utilised for estimating the dip direction of the geophysical bod-ies.

The 3D density modelling has been carried out using the IGMAS+ software (the Interactive Gravity and Magnetic Application System), described by Götze (1978), Götze \& Lahmeyer (1988), Schmidt \& Götze (1998) and Götze \& Schmidt (2010). The initial 3D model has been constructed by triangulation between the expected top and base of each crustal block along predefined vertical slices. The initial 3D geometry has been adjusted during the 3D density modelling. The geometrical approximation for the shape of the crustal blocks is based on a complex 3D mesh, represented by multiple polyhedra with triangulated planes between the top and the base of each crustal block and constant densities and magnetic susceptibilities have been assigned to these polyhedra. The integral gravity effect of all triangulated polyhedra of the 3D structural model corresponds to the total gravity effect of the 3D model. This gravity effect has been modelled to fit the observed gravity field as much as possible.

The process of the 3D density modelling is based on interactive changes of the geometry and density along E-W-oriented, predefined, vertical slices through the 3D structural model (Fig. 12). The shape of the crustal blocks has been changed manually during the 3D model-ling, whereas values of density have been taken both manually and automatically. The 2D working slices have been set to be parallel to each other and to cross the most important gravity anomalies and the major tectonic units of the study area 

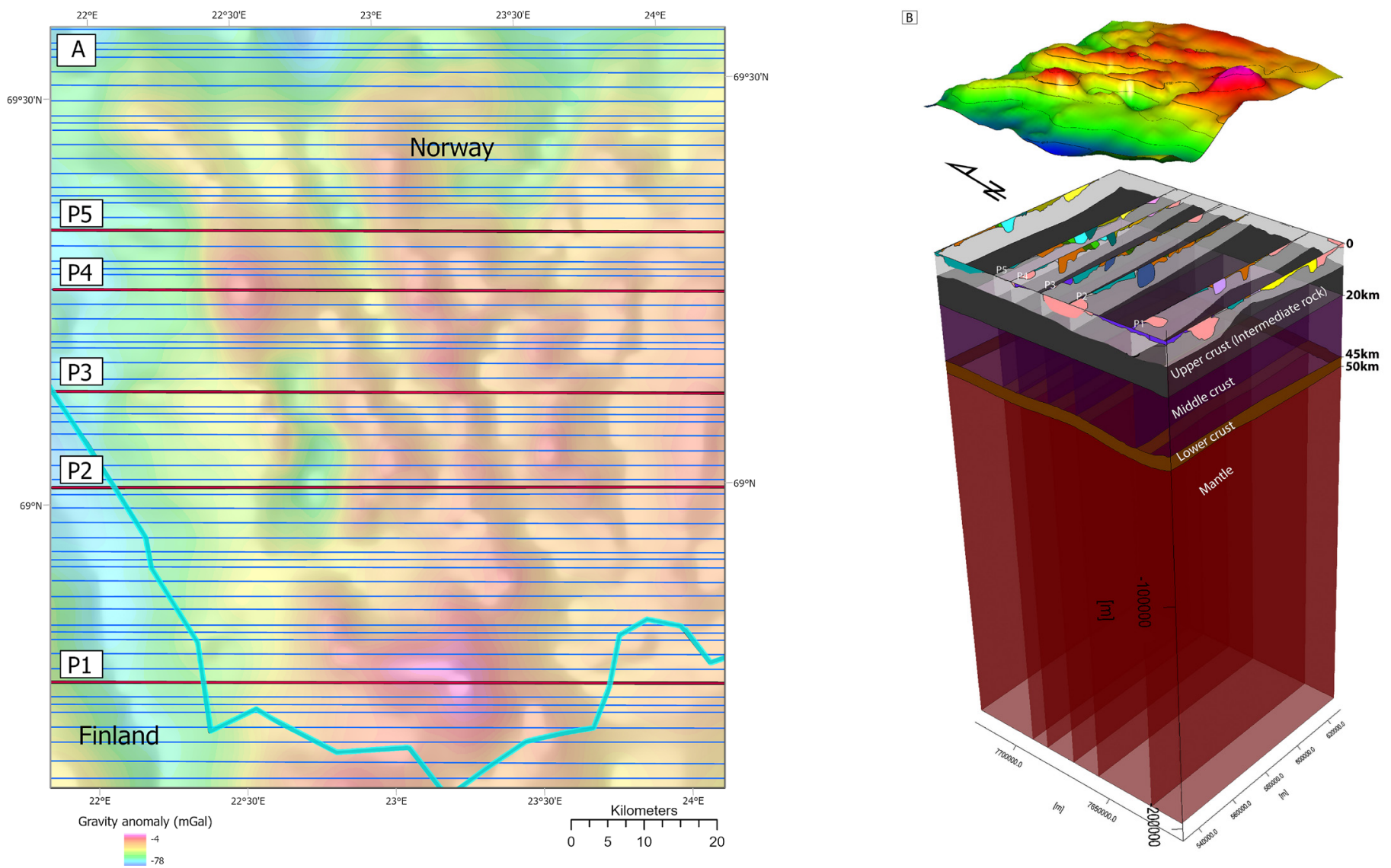

Figure 12. (A) Location of the 2D vertical slices through the 3D density model (blue lines). The red lines show the selected vertical slices discussed in the present paper (P1-P5). (B) 3D model of the area which shows the selected profiles with the numbers (P1-P5).

to avoid possible artefacts due to 3D triangulation between the vertical slices. To avoid edge/boundary effects, the 3D model has been laterally extended in all directions, exceeding the actual model area. Table 1 summarises the different layers, formations and also intrusive bodies that have been used for the construction of the 3D model.

An inherent non-uniqueness of the applied methodology has already been described in detail by Maystrenko et al. (2017). Here, we would like to emphasise that the major uncertainty of the potential field modelling is related to the fact that structurally different density or mag-netic models can be responsible for similar modelled gravity or magnetic fields. During the modelling, this ambiguity of the method has been reduced by considering the lateral influ-ence of the crustal blocks in 3D and by the use of constraining data such as geological maps and petrophysical data. It is also obvious that the uncertainties increase with depth due to a deficit or even lack of information about the composition and geometry of the deep crust.

\section{Results of the 3D density modelling}

The measured data and calculated field response from the $3 D$ density model are shown in Figs. 13A \& 13B. The regional field and also the residual field have also been depicted (Figs. 13C \& 13D). The regional field modelling of the area was carried out by using published Moho maps (Silvennoinen, 2014) of the region and also adopted a crustal model from the FENNOLORA seismic line (Guggisberg et al., 1991). Therefore, the middle and lower crust and Moho topography have been constructed based on the previous studies (Guggisberg et al., 1991; Silvennoinen et al., 2014). 
The upper crust has been subdivided into three parts: (1) an intermediate layer with a higher density of $2800 \mathrm{~kg} / \mathrm{m3}$; (2) an upper granitoid layer with the Jergul and Ráiseatnu gneiss complexes as the main rock units of this layer; and (3) different supracrustal layers (including KKGB metavolcanic rocks and several granitic intrusions together with sedimentary layers). The modelled data are not as smooth as the measured data due to the distance between the modelled vertical slices through the 3D model in addition to the complexity of the real geology which was reasonably simplified during the 3D modelling. In order to provide insights into the 3D modelling, our results will be presented by several vertical slices through the 3D density/structural model (P1-P5 in Figs. 12A \& 13). Those sections (slices) have been chosen to crosscut some of the main geophysical anomalies.
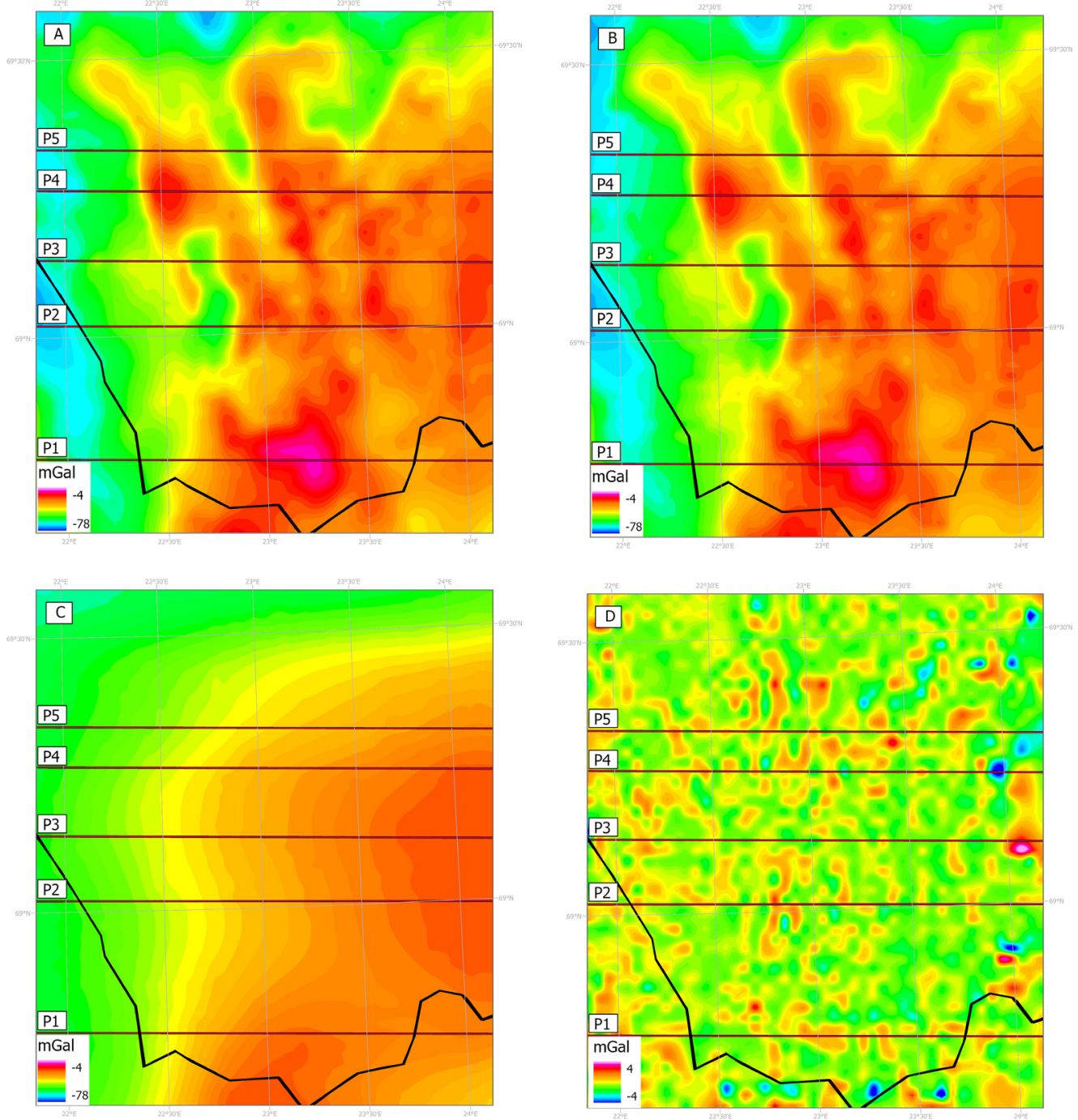

Figure 13. Measured and calculated gravity fields. (A) Measured data, (B) calculated data, (C) regional field and (D) residual gravity field (subtraction of the calculated field from the measured data). P1-P5: selected profiles with the numbers.

\section{Section P1}

This section, from east to west, crosses a granitic body (Hætta Complex in northern Finland, Fig. 2) and several linear geological features, including $\mathrm{N}$-S-oriented mafic dykes extending northwards from Finland (Fig. 14). Also, it crosses the KKGB, including the Ráiseatnu Gneiss Complex. The eastern part of the section crosses the northernmost part of a large granitic/granodioritic intrusion, a large part of which is located in Finland. The gravity along the profile is characterised by a decreasing regional 

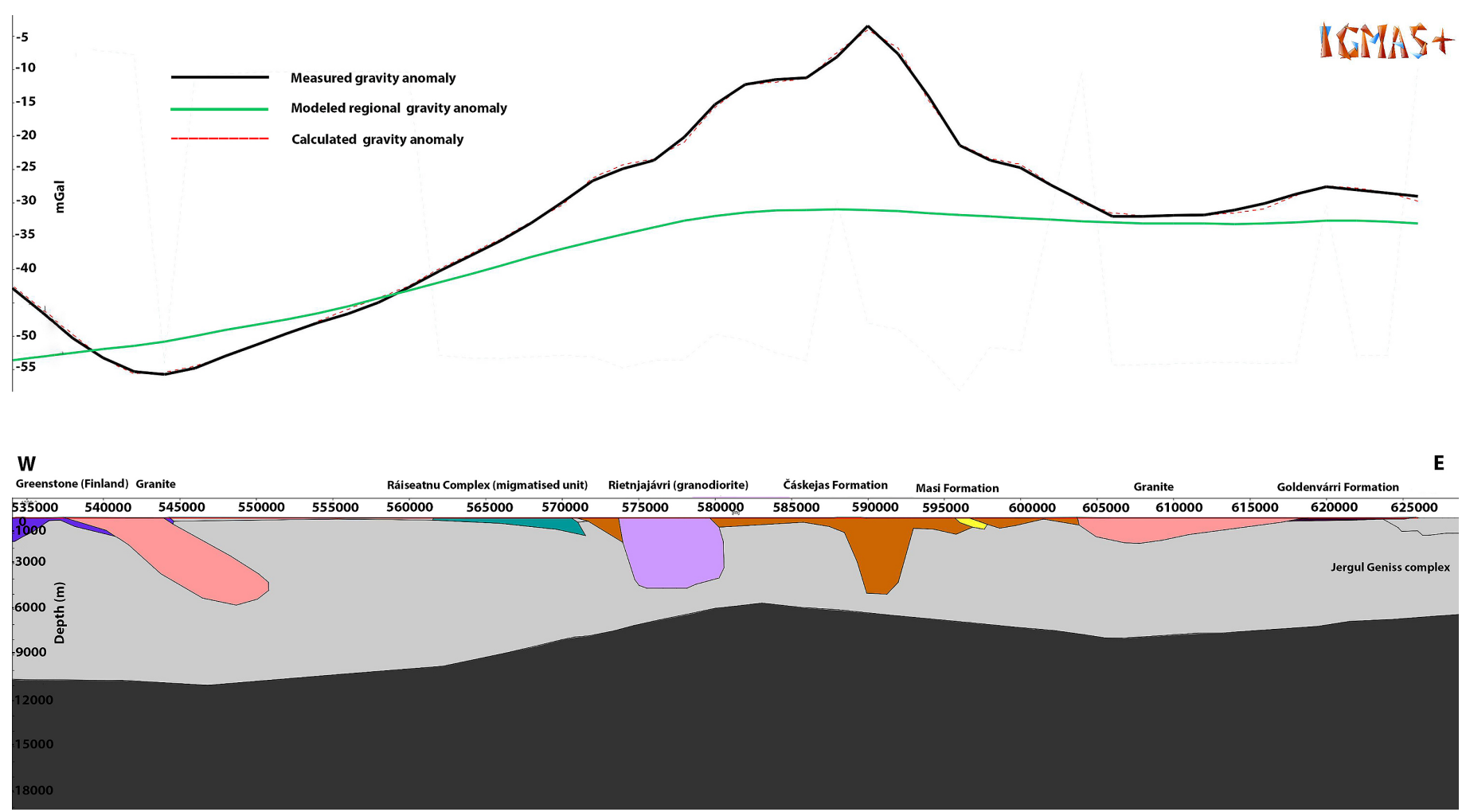

Figure 14. Selected vertical slice P1 through the 3D density/structural model in Fig. 10. The black line shows the measured data. The dashed red line is the modelled data, and the green line shows the regional trend.

trend from east to west. It is obvious that the intermediate crustal layer has had a major impact on the regional field in our model. Lindroos \& Henkel (1978) interpreted the large gravity anomaly from northern Sweden/Finland by introducing a large intermediate rock unit. According to these authors, the outcropping intermediate gneisses have a positive density contrast to the uppermost granitoid layers in the crust which are also exposed in the Jergul and Rommaeno gneiss complexes. The intermediate-density rocks are exposed in Finland and Sweden within the central part of the correlated Norrbotten complex (Lindroos \& Henkel, 1978) and in the Lofoten-Vesterålen area (Griffin et al., 1978; Olesen et al., 1991). Noteworthy, the deeper layers of the 3D density model were kept almost horizontal or with a very gentle dip. This includes the Moho boundary as well. The reason is that we do not have reliable information from large depths for this region. In any case, these deep layers are (sub-)horizontal according to the FENNOLORA seismic line (Guggisberg et al., 1991).

Section P2

This section, from east to west, crosses the Jergul Gneiss Complex and several portions of KKGB, including the oldest greenstone unit, the Goldenvárri Formation (Fig. 15). The regional field is assumed to have a linear trend increasing from west to east. This section crosses the Ádjit dome (Olesen \& Sandstad, 1993), which is clearly distinguished by a pronounced gravity low. On the published geological maps, the Ádjit dome is considered as either a quartzite unit similar to the Masi quartzite or a mixture of granitic and quartzitic rocks. In the current model, a low-density value is considered to mimic the observed gravity low. The assigned density $\left(2600-2630 \mathrm{~kg} / \mathrm{m}^{3}\right)$ is most likely related to granitic rocks because the Masi quartzite rocks have a slightly higher density $\left(2640 \mathrm{~kg} / \mathrm{m}^{3}\right)$. At the easternmost part of the profile, a positive gravity anomaly is observed. This anomaly has almost the same magnitude as the greenstone belt rocks, but it has not been mapped. It is possible to assume that this positive anomaly is associated with the same type of rocks as the Goldenvárri Formation. 


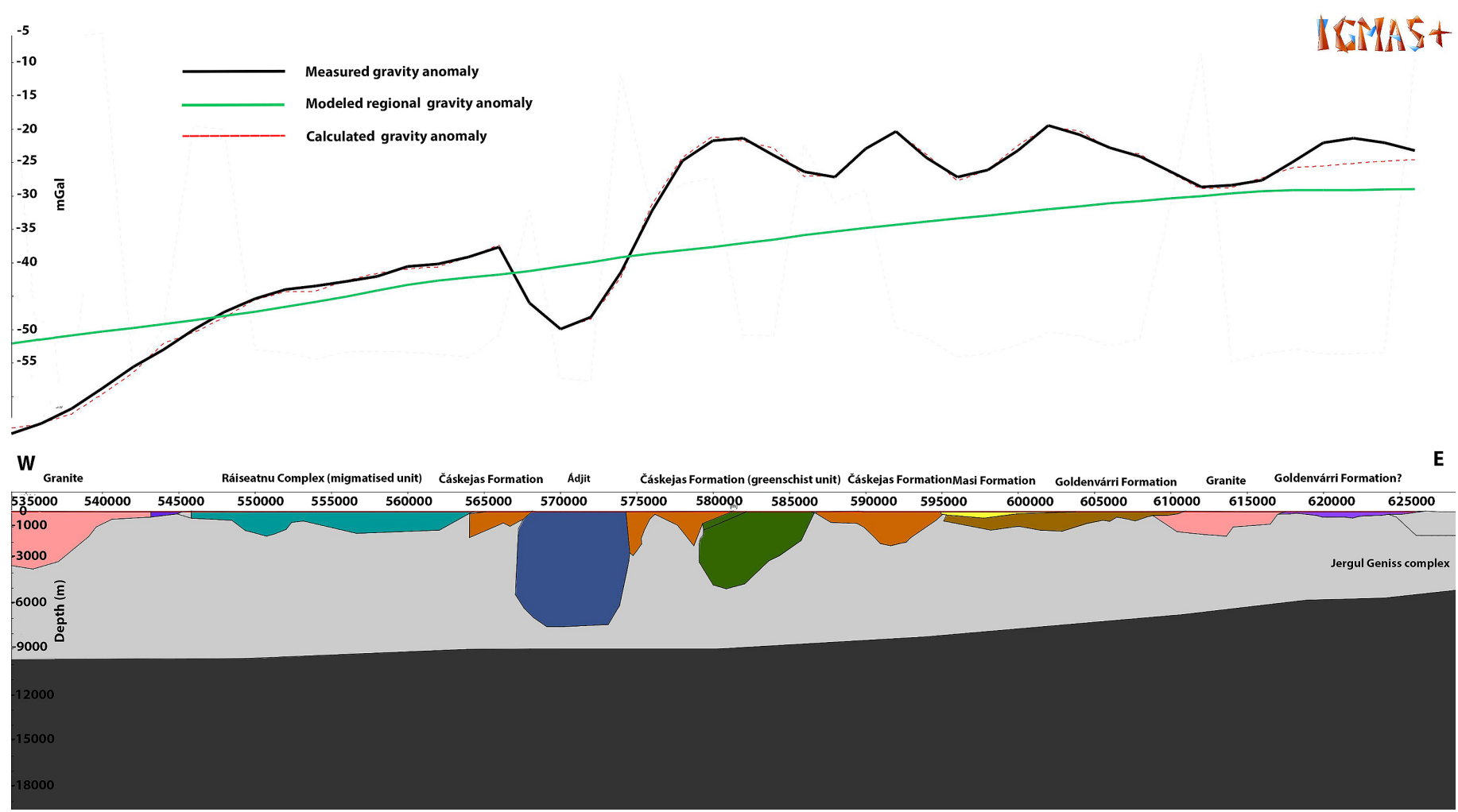

Figure 15. Selected vertical slice 2 (P2) through the 3D density/structural model in Fig. 12. The black line shows the measured data. The dashed red line depicts the modelled data, and the green line shows the regional trend.

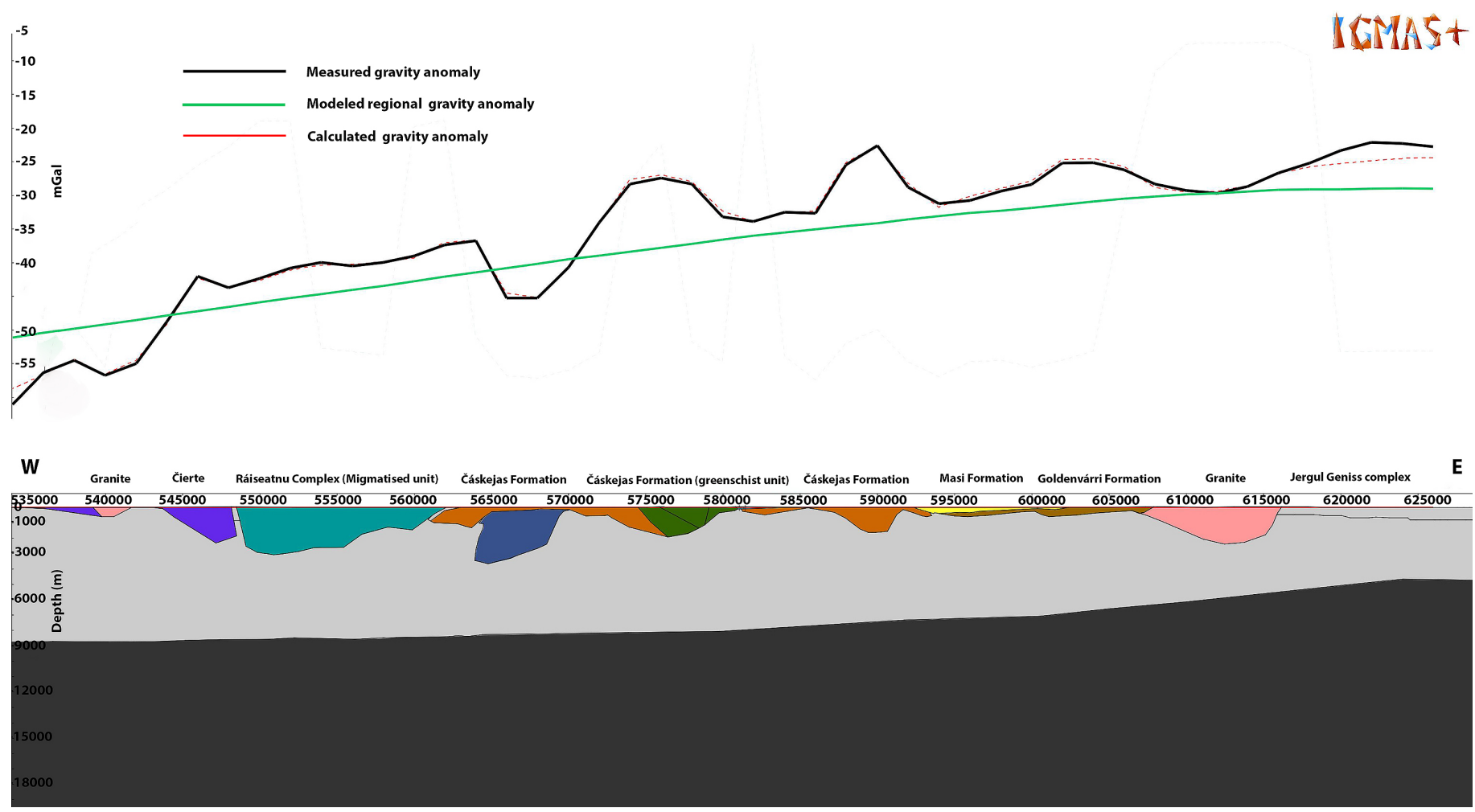

Figure 16. Selected vertical slice 3 (P3) through the 3D density/structural model in Fig. 12. The black line shows the measured data. The dashed red line is the modelled data and the green line shows the regional trend. 
This suggestion is also applicable to explain the presence of the $\mathrm{N}$-S-oriented gravity anomaly inside of the JGC within the eastern part of the next section (P3; Fig. 16). Our results indicate that the Ádjit structure can reach down to a depth of 7-8 km. A chain of low-amplitude negative and positive gravity anomalies can be seen to the west of Ádjit that is related to low-density granitic or high-density amphibolitic rocks, respectively. The migmatic rocks of the Ráiseatnu Gneiss Complex (Fig. 2) are reflected by a gentler gravity variation compared to the Jergul Gneiss Complex. The westernmost part of the profile with the pronounced negative gravity is located in Finland and can be represented by a granitic body.

Section P3

This section has been selected to demonstrate the extension of the Ádjit anticline underneath the volcanosedimentary rocks of the Čáskejas Formation (Figs. 2 \& 16). The regional gravity field along this section is very similar to the previous slice (cf., Fig. 15). The regional component of the gravity field can be simulated as a linear trend increasing to the east. Compared to the previous section (P2), the local anomalies are more distinctive and have higher magnitudes. The extension of the Ádjit structure is recognised by the presence of the negative gravity anomaly (Fig. 12). This structure is located underneath the Čáskejas Formation on the geological map as pointed out by Olesen \& Solli (1985). The corresponding gravity low of this structure is surrounded by positive gravity anomalies. In the 3D model, those anomalies are modelled by high-density amphibolitic rocks of the KKGB.

This section also highlights some short-wavelength anomalies located within the Ráiseatnu Gneiss Complex. These anomalies look similar to the KKGB anomalies. Some of these anomalies are related to the Čierte greenstone formation (Fareth et al., 1977) which is partly exposed and, therefore, has been successfully mapped at the surface Fig. 2).

In order to fit the modelled gravity with the observed one, we need to introduce several high-density rock units similar to high-density units of the KKGB both in the Ráiseatnu and also in the Jergul gneiss regions. The latter points to a necessity for modification/improvement of the geological map in these areas. This necessity is also highlighted by the high mismatch between the calculated and the measured gravity fields.

Section 4 (P4)

This section, from east to west, crosses the Jergul Gneiss Complex and the Masi Formation and after cross-cutting all major KKGB formations, ends in the Caledonian rocks. It is noteworthy that this slice crosses one of the largest gravity anomalies within the KKGB which is related to the Čáskejas formation. This unit has been traced to at least $6 \mathrm{~km}$ depth (Fig. 17). The regional field is also modelled to have a gentle decreasing trend from east to west as in the case of section P3. The dips of the KKGB formations are variable. Along this profile, it is assumed that, for example, the Čáskejas and Bihkkačohkka formations are dipping to the east (Fig. 17). 


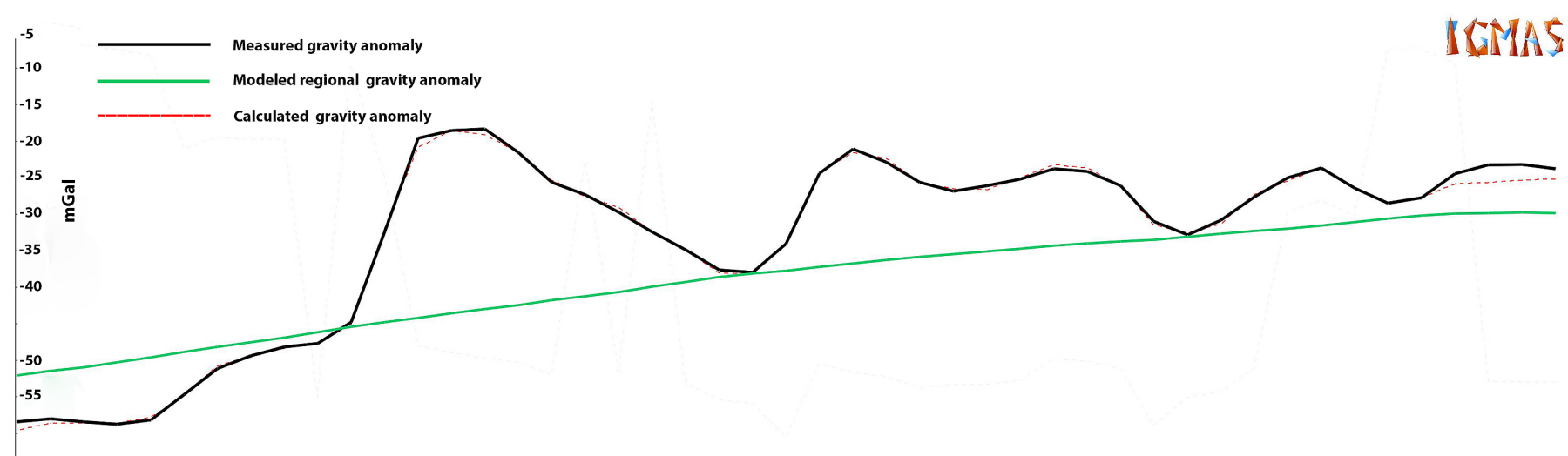

W

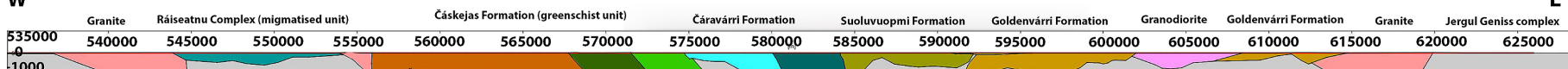

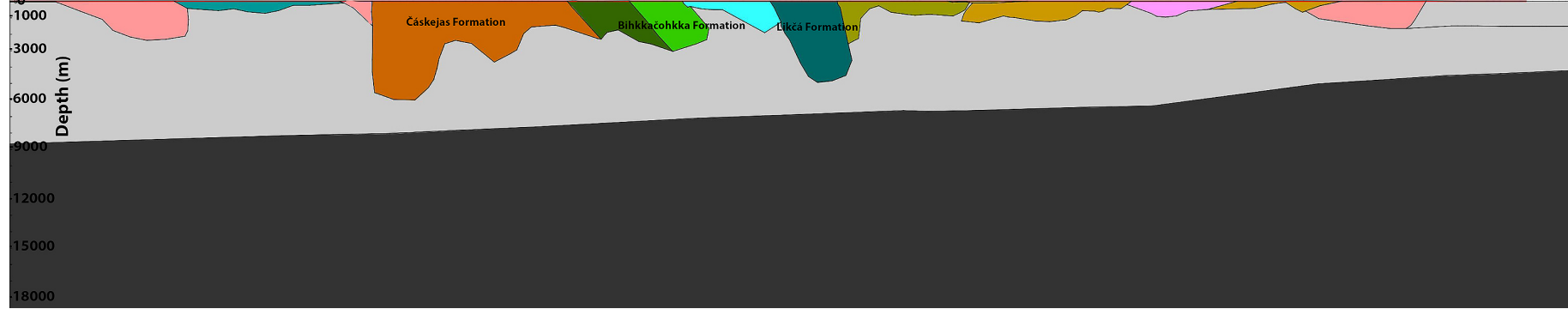

Figure 17. Selected vertical slice 4 (P4) through the 3D density/structural model in Fig. 12. The black line shows the measured data. The dashed red line represents the modelled data while the green line shows the regional trend.

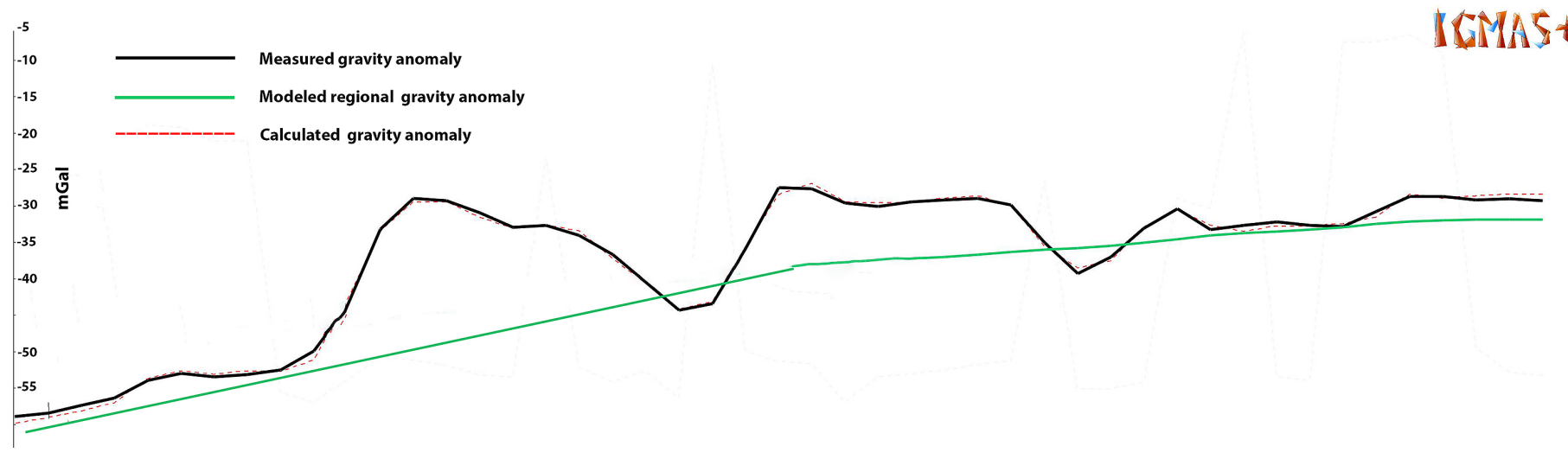

W

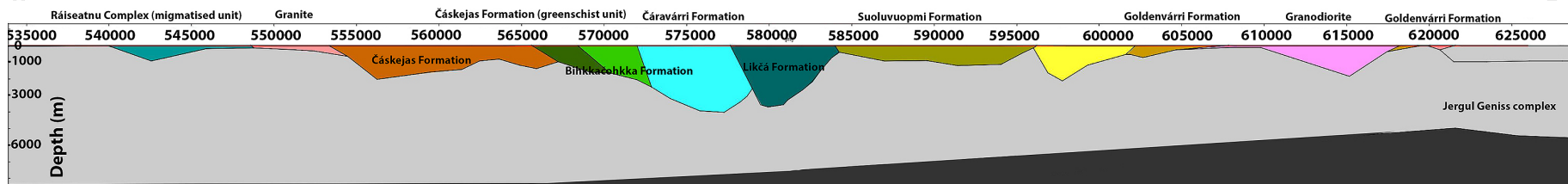

Figure 18. Selected vertical slice 5 (P5) through the 3D density/structural model in Fig. 12. The black line shows the measured data. The dashed red line depicts the modelled data, and the green line shows the regional trend. 
Section 5 (P5)

Section P5 is very similar to the previous one, but it has been chosen to demonstrate the lowest gravity values over the Čáravárri Formation (Fig. 18). The slice shows that this formation can reach a depth of 4-5 km. The thickness of the Masi Formation reaches $2 \mathrm{~km}$ along the profile. On the other hand, this section also crosses the Caledonian nappes where the anomalies maintain the same shapes, indicating that the Caledonian rocks are thin in this region. The Suolovuopmi Formation is represented by an almost horizontal layer along this section, whereas the western formations (e.g., Čáravárri Fm.) are steeply dipping towards the east.

\section{Discussion}

\section{Surface mapping}

Based on the results from analysing gravity and magnetic data (maps), we can interconnect the geophysical anomalies with the geological features (e.g., Figs. 7-9). Enhancement methods such as vertical gradient, analytical signal and tilt-derivative maps reveal the subtle anomalies which are hidden by the regional component of the gravity or magnetic fields. Due to differences in resolution between the available gravity and magnetic data, the gravity maps highlight the large- to medium-size structures of the region, whereas the new high-resolution magnetic data can decipher very fine details. The main strikes of the KKGB are well depicted by these data. The main trends of anomalies are NE-SW and NNW-SSE. These trends have been already discussed in previous studies (Olesen \& Sandstad, 1993; Henderson et al., 2015). The NE-SW trend is cross-cut by the presumably younger NNW-SSE-trending Bothnian-Kvænangen Fault Complex. Based on the fact that the KKGB is highly sheared and folded between the Jergul and Rommaeno gneiss complexes, several high-strain, sinistral shear-zones with duplex arrays have been recognised (e.g., Fig. 9, see also Henderson et al., 2015). Actually, gravity anomalies show both similarities and differences in comparison to their magnetic counterparts. For example, the magnetic map from the Ráiseatnu Gneiss Complex shows a very similar pattern to the main KKGB but the gravity anomalies are irregular and do not follow the same trends compared with the magnetic anomalies (Fig. 9B). This can be explained either by the lower resolution of the gravity data or by a difference between deeper and shallower anomalies. In other words, the deep-seated gravity sources may differ from highly magnetic anomalies in the shallower subsurface which are most likely represented by the migmatised rocks of the KKGB (e.g., Olesen \& Sandstad, 1993; Bingen et al., 2016). Alternatively, these high gravity anomalies can be associated with similar rocks of the KKGB which are covered by the Quaternary overburden. Comparison of the surface geology maps of Finland and Norway reveals that several gravity and magnetic anomalies can be traced from Finnish territory across the national border to Norway, including several portions of greenstone rocks (mafic metavolcanic rocks; Fig. 2). Due to the lack of surface geology data in the Ráiseatnu region, we have extrapolated only the near border bedrock units. However, the geological settings of the Jergul and Ráiseatnu areas, based on geophysical data, look to be much more complex than shown in the existing geological maps. Therefore, these maps should be modified and updated to be closer to the real geology. Detailed magnetic map analysis also helps us to recognise several new brittle and ductile faults/ shear zones (Fig. 9). Some of these newly-recognised faults have NE-SW-striking trends across the Finland-Norway border. Due to the presence of tectonic/structural discontinuities, a set of discordances disturbs or disrupts the anomaly pattern with a clear displacement or truncation. Ductile structures are reflected in smooth deflections and brittle structures are identified by the abruptly truncated anomalies. Besides the recognised rounded or oval-shaped magnetic anomalies, which are mostly related to granitic domes, there is also a distinctive deformed rounded anomaly 
between Čierte and Ádjit (Figs. 8 \& 9). This anomaly is not reflected by any structures in the geological maps. The magnetic pattern of this anomaly indicates that it is most likely bordered by two faults from the south and north. This anomaly is clearly recognised by several banded anomalies (onion ring shaped) in the magnetic maps. In contrast, this structure is not depicted on the gravity map (Fig. 10B). The exception is, however, on the TDR map of gravity (Fig. 9C), where this magnetic anomaly is reflected by a positive tilt-derivative value. Geologically, this anomaly may be related to amphibolitic rocks or an intrusion of intermediate or mafic composition (e.g., gabbro) in this region.

\section{D depth modelling}

A 3D geophysical/geological modelling over highly deformed and folded crystalline rocks is a challenging task. Building a 3D geological model at a crustal scale is challenging due to the inherent lack of information at depth. To build a geologically meaningful model, one must integrate all available geological and geophysical data. In the current study, geophysical and petrophysical data together with surface geological information have been used for constructing the 3D model of the KKGB. The gravity and magnetic data cover the whole region, but there is almost no information about the deep structure of the study area. Except for a regional-scale deep seismic line FENNOLORA (Guggisberg et al., 1991), some sparsely broadband seismic stations (Silvennoinen et al., 2014) and a $24 \mathrm{~km}$ long combined reflection seismic and magnetotelluric (MT) line in the Masi area (Mrope et al., 2019; Ruud et al., 2021; Olesen et al., 2021) which crosses the northeastern part of the KKGB in the Masi area (Fig. 4), there are no other sources which could constrain our model at great depth. Therefore, the regional potential field modelling within the study area is based on few and relatively poor observations. By knowing these limitations, the 3D model is simplified at great depth. For example, the middle crustal layer is kept almost unchanged throughout the modelling except in the northernmost part of the 3D model near the Caledonian front, where a sudden change in the regional gravity anomaly is observed (Fig. 7A). In contrast, the Moho depth and configuration of the high-density layer in the upper crust (intermediate rocks) have the main impact on the regional field in our model (Figs. 12-16). Lindroos \& Henkel (1978) modelled the large positive gravity anomaly between Karesuando and Hukki at the Sweden-Finland national border (south and southwest of our study area) by introducing a culmination composed of mafic-intermediate rocks. The proposed 3D structure of our study area follows the same hypothesis and explains the long-wavelength gravity anomaly by changing the upper surface of the intermediate rock layer (Figs. 14-18). In this respect, the relative high gravity values, extending from the southwest to the northeast, can explain a difference in the gravity fields from the Ráiseatnu Gneiss Complex (RGC) to the Jergul Gneiss Complex. This also indicates that the Ráiseatnu Gneiss Complex can be not only differentiated from the Jergul Gneiss Complex at the surface by comparing their magnetic signatures but also at depth with overall different compositions. To reduce the complexity of the 3D model, this difference is explained by the different depth of the intermediate rock layer rather than assuming a different layer for the RGC.

The 3D model shows that the depth extension of the KKGB varies considerably from a few hundred metres to 7-8 km. The largest and thickest portion of the greenstone belt belongs to the Čáskejas Formation in both the north and the south. Also, the Likčá Formation in some places reaches a depth of $8 \mathrm{~km}$ based on the 3D density modelling since the assigned density for the Likča Formation is lower than the one for the Čáskejas Formation (Fig. 19). It is also obvious that the dipping direction of the structures varies from south to north. In this regard, the magnetic data have been utilised to estimate the dipping direction of the geological units. The general flower structure of the KKGB interpreted by Henderson et al. (2015) is consequently not valid for the whole length of the greenstone belt. 


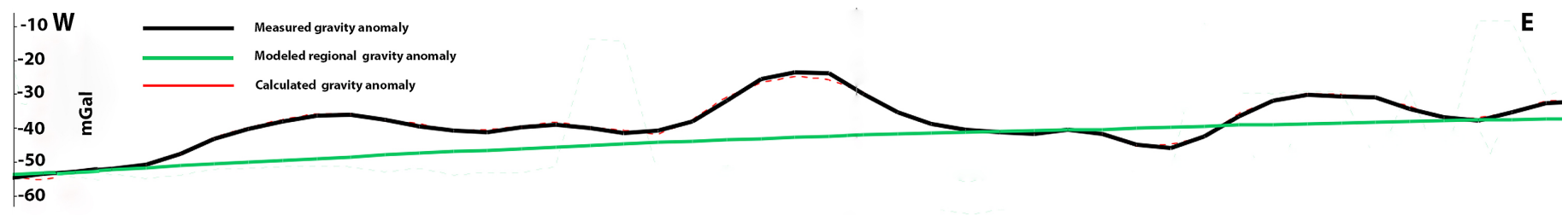

Cáskejas Formation (Amphibolites) Čáskejas Formation (Greenschist) Bihkkačohkka Formation Cáravárri Formation Likčă Formation Suoluvuopmi Formation Gran Masi Formation Goldenvárri Formation Granodiorite
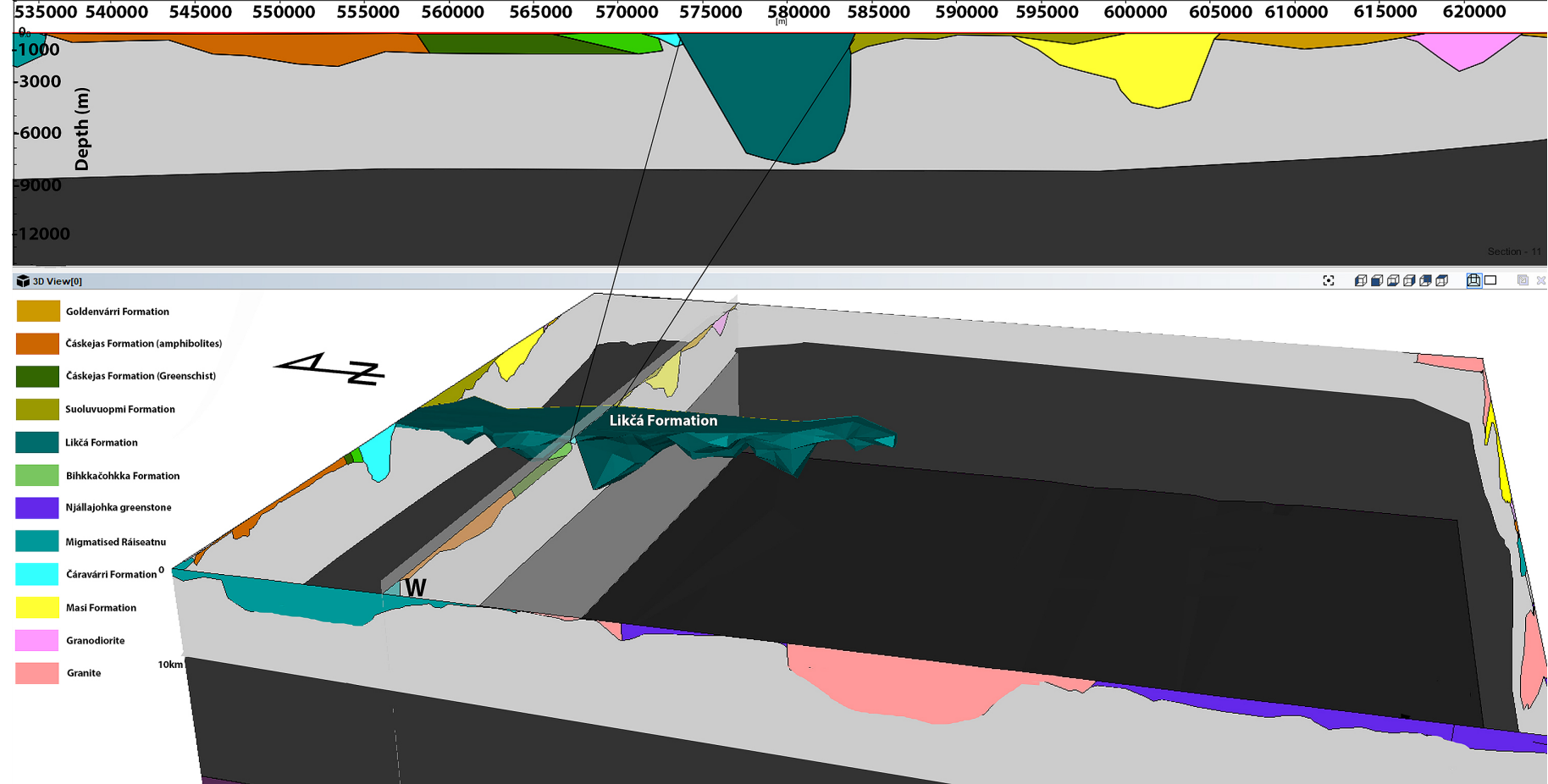

Figure 19. A 2D section and 3D view of the constructed model. The top panel shows a 2D section from the model with the main lithological units. The lower panel shows the 3D modelled structure of the Likčá Formation.

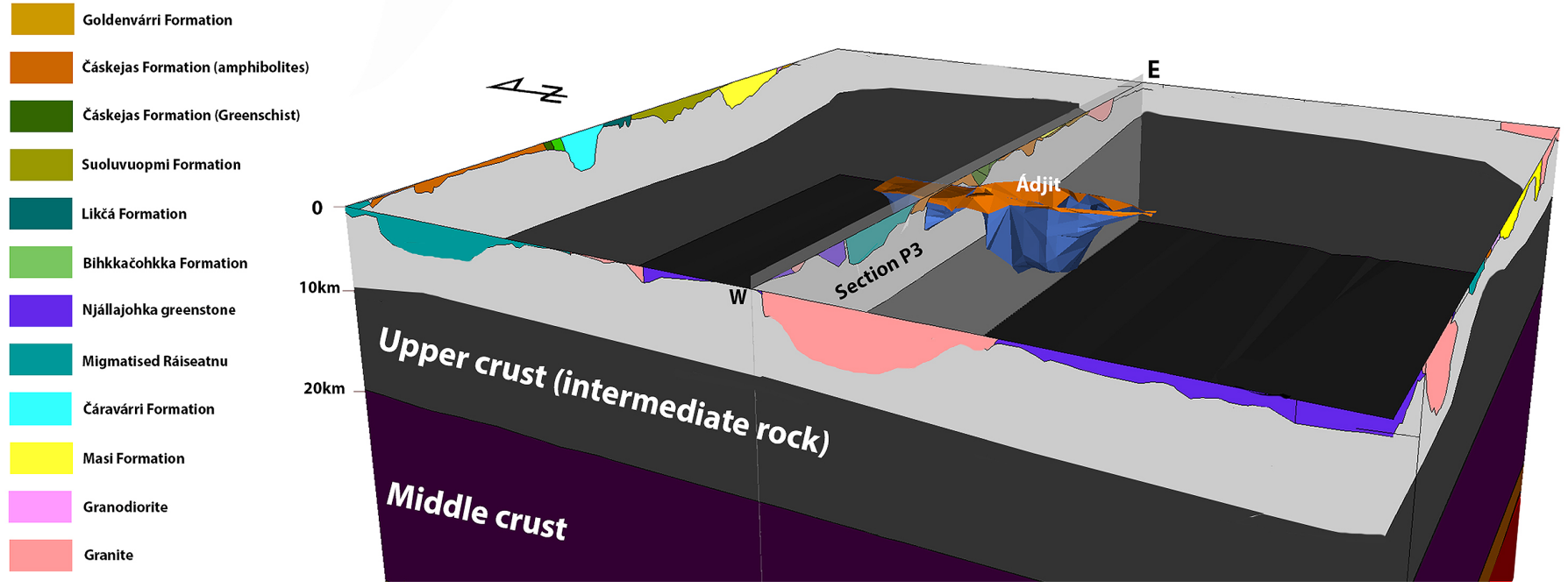

Figure 20. 3D density model of the Ádjit structure and its northern extension. The geological map is superimposed on the model, and section P3 is also shown (see Figure 14 for the vertical section P3). 
The previously studied rock units (structures) such as the Ádjit (Olesen \& Sandstad, 1993) have been modelled along 2D lines. Our results indicate, however, that the Ádjit structure is caused by a voluminous granite body with a large depth extension (7-8 km, see Fig. 15) that differs from previous interpretations that assumed the presence of a gneiss-quartzite dome. The new interpretation is supported by the old geological map by Holmsen et al. (1957) showing that this dome structure is composed of equal amounts of granitic and quartzite rocks. However, in the later and modified map (Olesen \& Sandstad, 1993), the dome structure is mainly composed of quartzites of the Masi Formation. The 3D model suggests a granitic body at depth with a possible layer of quartzitic sandstones on top of it. The density of this structure is assumed to be $2.6-2.63 \cdot 10^{3} \mathrm{~kg} / \mathrm{m}^{3}$ to mimic the observed anomaly. Therefore, in terms of density contrast, a quartzite or a granitic body may both fit for the modelled body but the main argument for introducing a granitic intrusion is the large depth extension of the low-density body. A similar but smaller domal structure can be recognised to the north of the Ádjit and seems to be an extension of Ádjit as also suggested by Olesen \& Solli (1985). In the 3D model these two domes are connected at depth with a varying depth extent. The latter has a depth of 3-4 km (Fig. 20).

The constructed model shows that the Masi Formation (Fig. 20) can be quite thick in several places and is possibly underlain by granitic/granodioritic rocks (e.g., Fig. 19). This agrees with the results from a recent study by Mrope et al. (2019) using MT and seismic data.

Within both the Jergul and the Ráiseatnu gneiss complexes (JGC and RaGC), there are several gravity anomalies that locally indicate dense rock units considered to be different from the Neoarchaean basement gneisses. In the current model, high-density rocks similar to the Čáskejas amphibolitic rocks are modelled to fit the observed and calculated gravity fields. However, due to the absence of surface observations, it is difficult to interpret them as the same rocks as greenstones or amphibolites. One of these anomalies, which has a deformed circular shape, is discussed in previous chapters. It is important to note that in some parts of the RaGC, we have mapped rocks similar to the KKGB (for example, in the south of Čierte and also along the Norway-Finland national border). These rocks can be traced by use of magnetic anomalies for several tens of kilometres. This may indicate that the RaGC partly comprises the same rocks as the KKGB.

The 3D density model (Fig. 21) shows that a set of high- and low-density structures fit the measured gravity anomalies of the region. Most of the positive gravity anomalies are caused by dense rocks of meta-volcanosedimentary rocks (Fig. 21B). In contrast, the negative gravity anomalies are assumed to be associated with a combination of quartzites/sandstones and granitoids (Fig. 21A). At a large scale, this Proterozoic greenstone belt has some similarities to the older Archaean counterparts, where most of the deformations are caused by gravitational forces. Where vertical tectonics are assumed to be the dominant mechanism they are possibly driven by the differences in density between the light granitic magmas in the domes and mafic and intermediate volcanic rocks which filled the adjacent basins. Later, due to compressional forces and horizontal shortening, the domes were squeezed, and this caused faulting and thrusting. This compressional tectonic event could have been followed by injection of the mafic dykes which are abundant in the KKGB region. Actually, most of the granitic domes in the KKGB area are surrounded by high-magnetic diabase sills and dykes.

To the west of the Ráiseatnu Gneiss Complex, a large and elongated granitic body has been modelled (Fig. 21A) which is partly depicted on the geological maps of Finland (Fig. 2). This granitic body is included to model the observed gravity low over that area. This gravity anomaly can be seen on the regional gravity and magnetic maps within the study area (Fig. 10), indicating a pronounced structure that most likely reflects a major geological process in the region. Unfortunately, a detailed investigation of the tectonic evolution of the Finnish part of the study area is outside the scope of the present study, but we think that the general geodynamical implications of our modelling have to be considered in future work. 

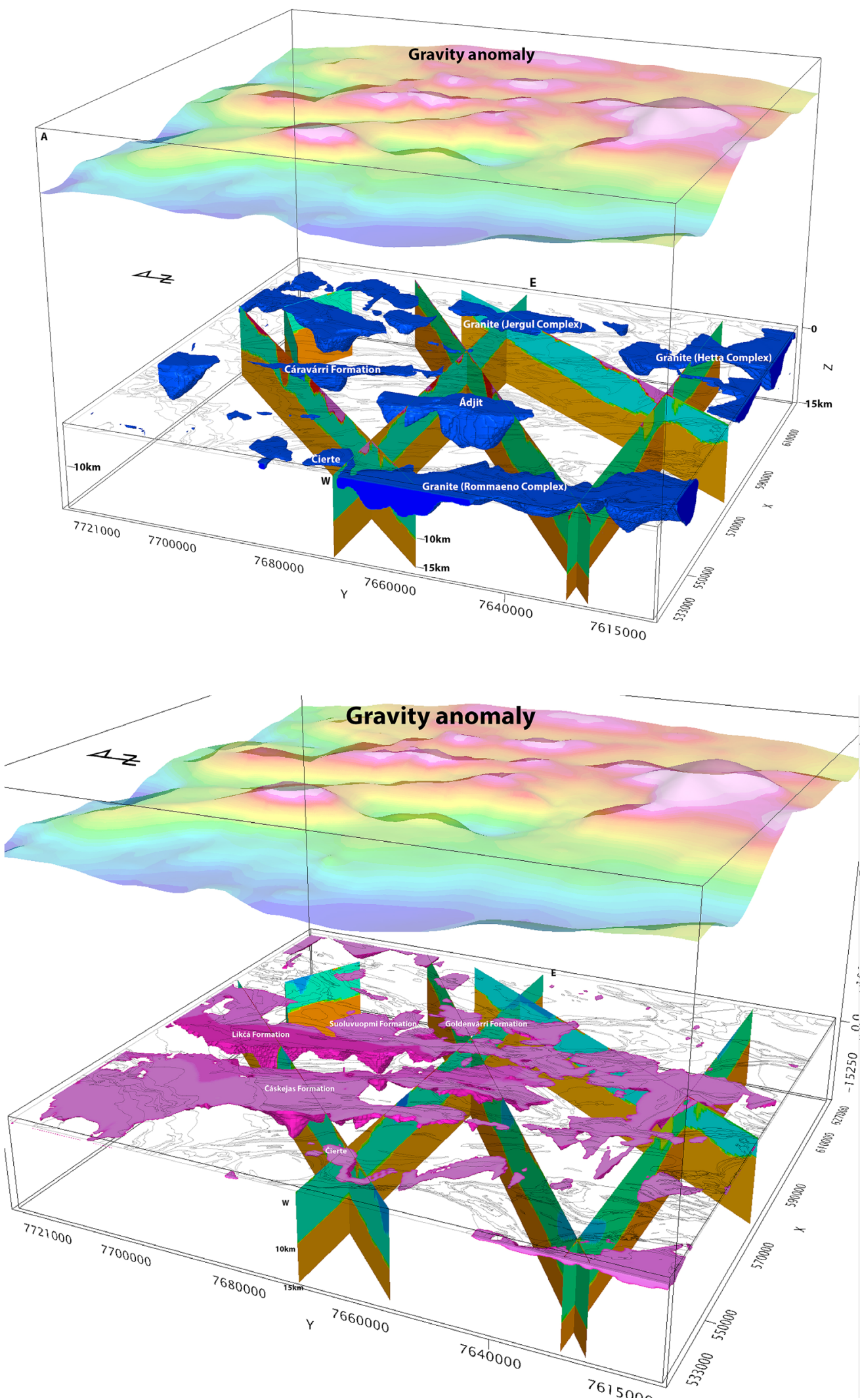

Figure 21. A 3D view at the constructed 3D model. (A)The bluish bodies (low-density rocks) are mainly granitic) granodioritic or sedimentary rocks (sandstone or quartzite) (B) Rocks with pinkish colours represent the thicker layer of high-density rocks of the KKGB (mainly amphibolite-facies mafic/ultramafic rocks). The 3D view only shows the rock units which have a thickness of more than $500 m$. 


\section{Conclusions}

A thorough 2D/3D gravity and magnetic analysis is presented for the Kautokeino Greenstone Belt (KKGB) and parts of the neighbouring Rommaeno and Jergul gneiss complexes. This has helped to follow the structures crossing borders from Finland to Norway. The analyses also suggest several modifications to the published geological maps from the region.

Several new ductile/brittle structures have been proposed. Some of these new structures require confirmation by surface geological mapping. Besides, distinct anomalies, related to the Jergul Gneiss Complex, may indicate an extension of the KKGB to the east.

A 3D density model of the KKGB is constructed using gravity data and constrained by magnetic and petrophysical datasets. The new 3D density model indicates that the KKGB is broader than it has been suggested before. The 3D analysis suggests that the belt reaches depths of at least 5-6 km and is emplaced as a highly deformed structure between the Archaean Jergul Gneiss Complex (JGC) to the east and the Archaean Rommaeno Gneiss Complex (RoGC) in the west.

We suggest that the RaGC represents a migmatised portion of the KKGB and thus representing a late phase of its development. A set of high- and low-density structures have been introduced during the modelling to reproduce the measured gravity anomalies over the region.

This study demonstrates that careful integration of geological and geophysical data can strongly improve our 3D understanding of the complex, poorly exposed, Precambrian terranes of the Finnmarksvidda region in Norway. Integrated 3D density modelling, constrained by surface geological mapping and petrophysical samples, helps to refine and establish a realistic 3D subsurface model of the area under consideration.

Acknowledgements. This contribution constitutes a part of the programme 'Mineral Resources in North Norway' (MINN) managed by Jan Sverre Sandstad of the Geological Survey of Norway. We also thank the Geological Survey of Finland (GTK) and the Geological Survey of Sweden (SGU) for providing the data from their respective countries. Many thanks go to Arne Bjørlykke for his valuable discussions and for sharing his excellent knowledge about our study area. We also thank Claudia Hasse for her help during the IGMAS modelling. We are also grateful to Kåre Kullerud and another anonymous reviewer for their thorough reviews of our manuscript and their valuable comments and suggestions which led to improvements in the final version. 


\section{References}

Airo, M-L. (ed) 2005: Aerogeophysics in Finland 1972-2004: Methods, System Characteristics and Applications. Geological Survey of Finland Special Paper 39. http://arkisto.gsf.fi/sp/SP39.pdf.

Bergh, S.G. \& Torske, T. 1986: The Proterozoic Skoadduvarri Sandstone Formation, Alta, Northern Norway: a tectonic fan delta complex. Sedimentary Geology 47, 1-25.

https://doi.org/10.1016/0037-0738(86)90068-0

Bergh, S.G. \& Torske,T. 1988: Palaeovolcanology and tectonic setting of a Proterozoic metatholeiitic sequence near the Baltic Shield margin, northern Norway. Precambrian Research 39, 227-246. https://doi.org/10.1016/0301-9268(88)90021-6

Berthelsen, A. \& Marker, M. 1986: Tectonics of the Kola collision suture and adjacent Archean and Early Proterozoic terrains in the northeastern region of the Baltic Shield, Tectonophysics 126, 31-55. https://doi.org/10.1016/0040-1951(86)90219-2

Bingen, B., Solli, A., Viola, G., Torgersen, E., Sandstad, J.S., Whitehouse, M.J., Rohr, T.S., Ganerød, M. \& Nasuti, A. 2016: Geochronology of the Palaeoproterozoic Kautokeino Greenstone Belt, Finnmark, Norway: Tectonic implications in a Fennoscandia context. Norwegian Journal of Geology 95, 365-396. https://doi.org/10.17850/njg95-3-09

Bjørlykke, A., Nilsen, K.S., Anttonen, R. \& Ekberg. M. 1993: Geological setting of the Bidjovagge deposit and related gold-copper deposits in the northern part of the Baltic Shield. Proceedings tram the 8th IAGOD Symposium 1990. Ottawa, Canada, 667.680.

Blakely, R.J. 1996. Potential theory in gravity and magnetic applications, Cambridge Univ. Press. 441 pp. https://doi.org/10.1017/CBO9780511549816

Cowan, D.R. \& Cooper, G.R.J. 2008: Merging radiometric grids using histogram matching: Computers \& Geosciences 34, 291-298, https://doi.org/10.1016/j.cageo.2007.05.012.

Daly, J.S., Balagansky, V.V., Timmerman, M.J. \& Whitehouse, M.J. 2006: The Lapland-Kola orogen: Palaeoproterozoic collision and accretion of the northern Fennoscandian lithosphere. Geological Society London Memoirs 32, 579-598.

Dickson, B.L. \& Scott, K.M. 1997: Interpretation of ariel ganmma-ray surveys - adding the geochemical factors. AGSO Journal of Australian Geology and Geophysics 17, 187-200.

Fareth, E., Gjelsvik, T. \& Lindahl, I. 1977: Cier'te, beskrivelse til det berggrunnsgeologiske kart 1733 II, scale 1:50,000 (med fargetrykt kart). Norges geologiske undersøkelse Skrifter 331, 28 pp.

Gaál, G., Berthelsen, A., Gorbatschev, R., Kesola, R., Lehtonen, M.I., Marker, M. \& Raase, P. 1989: Structure and composition of the Precambian crust along the POLAR Profile in the northern Baltic Shield. Tectonophysics 162, 1-25. https://doi.org/10.1016/0040-1951(89)90354-5

Geological Surveys of Finland, Norway and Sweden 1986a: Aeromagnetic anomaly map, Northern Fennoscandia, 1:1 mill., Helsinki. /SBN.9 1·7158·375·0 . 
Geological Surveys of Finland, Norway and Sweden 1986b: Aeromagnetic interpretation map, Northern Fennoscandia, 1:1 mill., Helsinki. /SBN-91-7158-376-9.

Geological Surveys of Finland, Norway and Sweden 1987: Geological map, Northern Fennoscandia, 1:1 mill., Helsinki. ISBN-91-7158-370-X.

Geosoft 2010: OASIS Montaj v7.2 Mapping and processing system, The core software platform for working with large volume spatial data. Quick start tutorials. Geosoft Incorporated, $325 \mathrm{pp}$.

Götze, H.J. 1978: Ein numerisches Verfahren zur Berechnung der gravimetrischen Feldgrosen drei-dimensionaler Modellkorper. Archives for Meteorology, Geophysics and Bioclimatology, Series A, 195-215. https://doi.org/10.1007/BF02246695

Götze, H.J. \& Lahmeyer, B. 1988: Application of three-dimensional interactive modelling in gravity and magnetics. Geophysics 53, 1096-1108. https://doi.org/10.1190/1.1442546.

Götze, H.J. \& Schmidt, S. 2010: IGMAS+: A new 3D gravity, FTG and magnetic modelling software tool, ASEG-PESA Airborne Gravity Workshop, Expanded Abstracts, 91-96, ISBN 978-1-921781-17-9.

Grant, F.S., 1985a. Aeromagnetics, geology and ore environments, I. Magnetite in igneous, sedimentary and metamorphic rocks: An overview. Geoexploration 23, 303-333.

https://doi.org/10.1016/0016-7142(85)90001-8

Grant, F.S., 1985b. Aeromagnetics, geology and ore environments, II. Magnetite and ore environments. Geoexploration 23, 335-362. https://doi.org/10.1016/0016-7142(85)90002-X

Griffin, W.L., Taylor, P.N., Hakkinen, J.W., Heier, K. S., Iden, I.K., Krogh, E.J., Malm, O., Olsen, K.I., Ormaasen, D.E. \& Tveten, E. 1978: Archaean and Proterozoic crustal evolution in Lofoten-Vesterålen, North Norway. Geol. Soc. Lond. 135, 629-647. https://doi.org/10.1144/gsjgs.135.6.0629

Guggisberg, B., Kaminski, W., \& Prodehl, C., 1991. Crustal structure of the Fennoscandian Shield: A traveltime interpretation of the long-range FENNOLORA seismic refraction profile. Tectonophysics 195 (2), 105-137. https://doi.org/10.1016/0040-1951(91)90208-A

Henderson, I.H.C., Viola, G. \& Nasuti, A. 2015: A new tectonic model for the Kautokeino Greenstone Belt, northern Norway, based on high-resolution airborne magnetic data and field structural analysis and implications for mineral potential. Norwegian Journal of Geology 95, 1-26.

https://doi.org/10.17850/njg95-3-05

Henkel, H. 1988 : Tectonic stud ies in the Lansjarv region. Svens k kii mbranslehanrering AB Technical Report 88-07. 166 pp.

Henkel, H. 1991: Magnetic crustal structures in northern Fennoscandia. In: Wasilewski, P. \& Hood, P. (eds.), Magnetic anomalies - land and sea. Tectonophysics 192, 57.79.

https://doi.org/10.1016/0040-1951(91)90246-0

Holmsen, P., Padget, P. \& Pehkonen, E. 1957: The Precambrian geology of Vest-Finnmark, northern Norway. Geological Survey of Norway Bulletin 210, 107 pp.

IAEA, 2003: Guidelines for radioelement mapping using gamma ray spectrometry, International Atomic Energy Agency, Technical Report Series, No. 1363. 
Isles, D.J., and Rankin, L.R., 2013: Geological Interpretation of Aeromagnetic Data. Australian Society of Exploration Geophysicists, CSIRO Publishing, 365 pp. https://doi.org/10.1190/1.9781560803218

Karinen, T., Lahti, I. \& Konnunaho, J. 2015: 3D/4D geological modelling of the Hietakero and Vähäkurkkio areas in the Lätäseno Schist Belt, Enontekiö, northern Finland. Geological Survey of Finland, Special Paper 57, 121-134.

Karinen, T., Lepistö, S., Konnunaho, J., Lauri, L.S., Manninen, T. \& Huhma, H., 2015: Yksikkökuvausraportti Enontekiö, Käsivarsi. Geological Survey of Finland, Archive Report 66/2015, 38 p.

Krill, A. 1985: Svecokarelian thrusting with thermal inversion in the Karasjok-Levajok area of the northern Baltic Shield. Norges geologiske undersøkelse 403, 89-101.

Koistinen, T., Stephens, M.B., Bogatchev, V., Nordgulen, Ø., Wennerström, M., Korhonen, J. (compilers) 2001: Geological map of the Fennoscandian Shield, scale 1:2 000 000. Espoo, Geological Survey of Finland; Geological Survey of Norway, Trondheim; Geological Survey of Sweden, Uppsala; Ministry of Natural Resources of Russia, Moscow.

Lindroos, H. \& Henkel, H. 1978: Regional geological and geophysical interpretation of Precambrian structures in north. eastern Sweden. Sver. geol. unders. C751, 19 pp.

Mathisen, O. 1976. A method for Bouger reduction with rapid calculation of terrain corrections. Geographic Survey of Norway Geodetic Publications 18, 40 pp.

Maystrenko, Y.P., Olesen, O., Gernigon, L. \& Gradmann, S. 2017: Deep structure of the LofotenVesterålen segment of the Mid-Norwegian continental margin and adjacent areas derived from 3D density modelling. Journal of Geophysical Research: Solid Earth 122, 1402-1433.

https://doi.org/10.1002/2016JB013443

Miller, H.G. \& Singh, V., 1994: Potential field tilt-a new concept for location of potential field sources, J. Appl. Geophys. 32(2-3), 213-217. https://doi.org/10.1016/0926-9851(94)90022-1

Mogaard, J.O. \& Skilbrei, J.R. 1986: Geofysiske målinger fra helikopter over kartbladene Kautokeino, Lappoloubbal. Norges geologiske undersøkelse Report 86.054, 21 pp.

Moore, G. 2008: Finland's national airborne geophysical mapping programme and the '3-in-1' approach. First Break 26, November, 79-85. https://doi.org/10.3997/1365-2397.26.1293.28610

Mrope, M.F., Becken, M., Ruud, O.B., Olesen, O., Johansen, T.A, Brönner, M., Gradmann, S. \& Nasuti, A. 2019: Magnetotelluric 2D inversion and joint interpretation of MT, magnetic and gravity data from Masi, Kautokeino municipality, Finnmark. NGU Report 2019.009, 64 pp.

Nabighian, M.N. 1972: The analytic signal of two-dimensional magnetic bodies with polygonal crosssection: its properties and use for automated anomaly interpretation, Geophysics 37(3), 507-517. https://doi.org/10.1190/1.1440276

Nabighian, M.N. 1984: Toward a three-dimensional automatic interpretation of potential field data via generalized Hilbert transforms: Fundamental relations: Geophysics 49, 780-786. https://doi.org/10.1190/1.1441706 
Nasuti, A., Roberts, D., Dumais, M.-A., Ofstad, F., Hyvönen, E., Stampolidis, A. \& Rodionov, A. 2015: New high-resolution aeromagnetic and radiometric surveys in Finnmark and North Troms: linking anomaly patterns to bedrock geology and structure. Norwegian Journal of Geology 95, 217-243.

https://doi.org/10.17850/njg95-3-10

Novatem 2012: Fixed wing magnetic and radiometric survey of the coastal area of Northwestern Norway (FRAS-E). Report no. C11089, Novatem Airborne Geophysics, Mont-Saint Hilaire, Quebec, Canada, 36 pp.

Ofstad, F., Baranwal, V., Koziel, J., Lynum, R. \& Rodionov, A. 2013: Helicopter-borne magnetic, electromagnetic and radiometric geophysical survey in Repparfjord area, Alta and Kvalsund, Finnmark. Norges geologiske unders $\varnothing$ kelse Report 2013.027, 25 pp.

Olesen, O. \& Solli, A. 1985: Geophysical and geological interpretation regional structures within the Precambrian Kautokeino Greenstone Belt, Finnmark, North Norway. Geological Survey of Norway Bulletin 403, 119-133.

Olesen, O. \& Sandstad, J.S. 1993: Interpretation of the Proterozoic Kautokeino Greenstone Belt, Finnmark, Norway from combined geophysical and geological data. Geological Survey of Norway Bulletin 425, 43-64.

Olesen, O., Roberts, D., Henkel, H., Lile, O.B. \& Torsvik, T.H. 1990: Aeromagnetic and gravimetric interpretation of regional structural features in the Caledonides of West Finnmark and North Troms, northern Norway. Norges geologiske undersøkelse Bulletin 419, 1-24.

Olesen, O., Reitan, M. \& Sæther, P.O. 1993: Petrofysisk database PETBASE 3.0, Brukerbeskrivelse. NGU Internal Report 93.023, 74 pp.

Olesen, O., Henkel, H., Kaada, K. \& Tveten, E. 1991: Petrophysical properties of a prograde amphibolite - granulite facies transition zone at Sigerfjord, Vesterålen, northern Norway. In Wasilewski, P. \& Hood, P. (eds) Magnetic Anomalies - Land and Sea. Tectonophysics 192, 33-39. https://doi.org/10.1016/0040-1951(91)90244-M

Olesen, O., Henkel, H., Lile, O.B., Mauring, E. \& Rønning J.S. 1992: Geophysical investigations of the Stuoragurra postglacial fault , Finnmark, northern Norway. Journal of Applied Geophysics 29, 95-118. https://doi.org/10.1016/0926-9851(92)90001-2

Olesen, O., Olsen, L., Gibbons, S., Ruud, B.O., Høgaas, F., Johansen, T.A. \& Kværna, T. 2021: Postglacial faulting in Norway - Large magnitude earthquakes of late Holocene age. In H. Steffen, O. Olesen, and R. Sutinen, (eds.), Glacially-Triggered Faulting, Cambridge University Press. pp. 198-217. https://doi.org/10.5194/egusphere-egu2020-21749

Olesen, O., Ebbing, J., Gellein, J., Gernigon, L., Koziel, J., Lauritsen, T., Mykelbust, R., Pascal, C., Sand, M., Solheim, A. \& Usov, S. 2010: New aeromagnetic and gravity compilations from Norway and adjacent areas - methods and applications. In Vining, B.A. \& Pickering, S.C. (eds.): Petroleum geology: from mature basins to new frontiers, Geological Society of London 7, 559-586.

https://doi.org/10.1144/0070559

Olsen, K.I. \& Nilsen, K.S. 1985: Geology of the southern part of the Kautokeino Greenstone Belt: $\mathrm{Rb}-\mathrm{Sr}$ geochronology and geochemistry of associated gneisses and late intrusions. Geological Survey of Norway Bulletin 403, 131-160. 
Ruud, B.O., Olesen, O., Gellein, J. \& Johansen, T.A. 2021: Acquisition, processing, and interpretation of snow-streamer seismic profiles in Masi and Sennalandet, Finnmark, northern Norway. NGU Report 2021.004, 35 pp.

Sandstad, J.S. 1983: Berggrunnsgeologisk kartlegging av prekambrisk grunnfjell innen kartbladet Mallejus, Kvrenangen/Kautokeino, Troms/Finnmark. NGU Report 1886/5, 28 pp.

Sandstad, J.S. 1985: Mallejus. Foreløpig berggrunnsgeologisk kart 1833 IV - 1:50.000. Norges geologiske undersøkelse.

Sandstad, J.S., 1992: Beskrivelse av digitalt framstilt berggrunnskart over Kautokeinogronnsteinsbeltet, Finnmark. NGU Report 92.250, 37 pp.

Schmidt, S. \& Götze, H.J. 1998. Interactive visualization and modification of 3D models using GIS functions. Physics and Chemistry of the Earth 23, 289-295.

https://doi.org/10.1016/S0079-1946(98)00027-5

Siedlecka, A., Iversen, E., Krill, A.G., Lieungh, B., Often, M., Sandstad, J.S. \& Solli, A. 1985: Lithostratigraphy and correlation of the Archean and Early Proterozoic rocks of Finnmarksvidda and the Sorvaranger district. Geological Survey of Norway Bulletin 403, 7-36.

Skilbrei J. R., Skyseth T., Olesen O. 1991: Petrophysical data and opaque mineralogy of high grade and retrogressed lithologies: implications for the interpretations of aeromagnetic anomalies in northern Vestranden, Western Gneiss Region, central Norway, eds Wasilewski P., Hood P. (Magnetic Anomalies - Land and Sea), 192, pp 21-31. https://doi.org/10.1016/0040-1951(91)90243-L

Silvennoinen, H., Kozlovskaya, E., Kissling, E., Kosarev, G., POLENET/LAPNET Working Group, Komminaho, P. \& Heikkinen, P. 2014: A new Moho boundary map for the northern Fennoscandian Shield based on combined controlled-source seismic and receiver function data. GeoResJ 1, 19-32, https://doi.org/10.1016/j.grj.2014.03.001

Solli, A. 1983: Precambrian Stratigraphy in the Masi Area, Southwestern Finnmark, Norway. Geological Survey of Norway Bulletin 380, 97-105.Solli, A. 1988: Masi, 1933 IV - berggrunnsgeologisk kart - M 1:50,000. Norges geologiske unders $\varnothing$ kelse, Trondheim.

Solli, A. 1988: Masi, 1933 IV - berggrunnsgeologisk kart - M 1:50,000. Norges geologiske unders $\varnothing$ kelse.

Solli, A. 1990: Čárajávri, 1983 I - berggrunnsgeologisk kart - M 1:50,000. Norges geologiske undersøkelse, Trondheim.

Torske, T. \& Bergh, S.G. 2004: The Čaravarri Formation of the Kautokeino Greenstone Belt, Finnmark, North Norway; a Palaeoproterozoic foreland basin succession. Geological Survey of Norway Bulletin $442,5-22$ 